\title{
LA CLÁUSULA ROMEO Y JULIETA (ART. 183 QUATER DEL CÓDIGO PENAL) CINCO AÑOS DESPUÉS: PERSPECTIVAS TEÓRICAS Y PRAXIS JURISPRUDENCIAL
}

\author{
José Antonio Ramos Vázquez*
}

Resumen: En este trabajo se estudia la cláusula Romeo y Julieta del Código penal español, es decir, la exención prevista en el art. 183 quater del Código penal para aquellos supuestos en que el menor de 16 años ha consentido tener relaciones sexuales con una persona próxima a él por edad y grado de desarrollo y madurez. Este análisis se hace desde dos puntos de vista: el estudio de las posiciones doctrinales existentes hasta el momento (de un lado) y el análisis sistemático de todas las sentencias que han recaído hasta el momento en aplicación de dicha cláusula. A través de ese doble análisis, el lector tendrá una visión clara de qué problemas plantea el precepto y, sobre todo, cómo se está aplicando en la praxis jurisprudencial.

Palabras clave: Derecho penal. Delitos sexuales. Abuso de menores. Consentimiento. Jurisprudencia.

\section{Recibido: febrero 2020. Aceptado: julio 2020}

* Titular de Universidad. ORCID: 0000-0001-7671-557X. Facultad de Derecho de la Universidad de A Coruña. Dirección Campus de Elviña. 15008. A Coruña. Email: jramosv@udc.es. 


\begin{abstract}
In this paper, the autor analyzes the Romeo and Juliet clause (art. 183 quater of the Spanish Penal Code), from two different perspectives: firstly, the main opinions of the authors who have dealt with this topic are studied. Secondly, the author analyzes all case-law regarding the enforcement of art. 183 quater.
\end{abstract}

Keywords: Criminal Law. Sexual crimes. Child sexual abuse. Consent. Case Law.

\title{
1. Introducción
}

"My child is yet a stranger in the world; / she hath not seen the change of fourteen years, / let two more summers wither in their pride, / ere we may think her ripe to be a bride". (SHAKESPEARE, Romeo y Julieta, acto 1, escena 2).

De este modo se dirigía el señor de Capuleto a Paris cuando éste le solicitó la mano de Julieta: destacando que aún no tenía los catorce años cumplidos y que era mejor esperar "dos veranos más" para pensar en el matrimonio. Como sabemos, Julieta terminará casándose poco después con Romeo, de quien no sabemos la edad, pero sí que todos los personajes se refieren a él como "el joven Romeo"1.

Pues bien, como con sorna señala JAMES, "dado que Julieta tiene sólo trece años y Romeo es un adolescente mayor, su romance podría enfrentarse a serios problemas respecto de la edad de consentimiento de relaciones sexuales. En muchos Estados, Romeo, y quizás Julieta, podrían ser detenidos y enfrentarse a una acusación penal a causa de su

1 En el poema de Arthur Brooke en que se basó Shakespeare para escribir su obra, se nos dice de Romeo que "fue de la estirpe de Montague / y en su tierna barbilla, aún no había crecido barba de hombre” (versos 55 y 56 ), por lo que podemos suponer que rondaba la edad de Julieta. 
edad. Y cuando te enfrentas a multitud de años en prisión y una inscripción de por vida en el registro de delincuentes sexuales, las rencillas entre dos familias no parecen gran cosa en comparación", concluyendo que "aunque la idea de Romeo y Julieta siendo juzgados como delincuentes sexuales puede parecer absurda, la realidad es que eso le ha pasado y le puede pasar a muchos adolescentes actuales" 2 .

En nuestro Estado, tras siglo y medio (de 1848 a 1999) en que la edad de consentimiento a efectos penales estaba establecida en los 12 años, y casi veinte años (de 1999 a 2015) en que fueron los 13, actualmente está fijada en los 16 años, una edad que se cuenta entre las más altas de nuestro entorno jurídico ${ }^{3}$ y que suscita, consecuentemente, el antedicho problema de proscribir los abusos sexuales a menores sin castigar a los muchos romeos y julietas que desarrollan su vida sexual por debajo de esos 16 años.

La fórmula utilizada por la Ley Orgánica 1/2015, plasmada en el actual artículo 183 quater del Código Penal, ha motivado críticas e interrogantes desde el mismo momento de su promulgación y son esas incertidumbres y esas críticas las que centran este trabajo, desde un doble punto de vista.

En primer lugar, analizaré las cuestiones problemáticas que la doctrina ha planteado respecto de la cláusula Romeo y Julieta prevista en nuestro Código Penal. Utilizaré un sistema mayéutico, con preguntas y respuestas, pues me parece importante que eventuales operadores jurídicos que puedan tener acceso a este trabajo sepan localizar las distintas problemáticas dentro del texto.

2 JAMES, S.: "Romeo and Juliet were sex offenders: an analysis of the age of consent and a call for reform", en University of Missouri-Kansas City Law review, número 78, 2009-2010, p. 241.

3 Ampliamente, en este sentido, FISCALÍA GENERAL DEL ESTADO, Circular 1/2017, sobre la interpretación del art. 183 quater del Código penal, p. 3 (disponible en https://www.boe.es/buscar/abrir_fiscalia. php?id=FIS-C-2017-00001.pdf -última consulta: 3 de febrero de 2020). 
En segundo lugar, se estudiarán (casi) todas las sentencias que han recaído en materia durante el período 20152019, analizando no sólo qué respuestas se dan en la jurisprudencia a los interrogantes planteados por la doctrina, sino cómo se resuelven otros interrogantes que la práctica, siempre multiforme y llena de matices, ha suscitado. Indico que son "casi" todas las sentencias, porque es difícil garantizar que las búsquedas de jurisprudencia a través de las bases de datos disponibles sean, a la postre, exhaustivas.

En todo caso, las sentencias aquí estudiadas las hemos localizado ${ }^{4}$ a través de sucesivas cadenas de texto ("menor de edad Y abuso sexual Y consentimiento", "menor Y edad Y desarrollo O madurez", etc.) y búsquedas por precepto (artículos 183 y 183 quater del CP), en la base de datos Tirant on line, homologada por el Centro de Documentación Judicial (en adelante, CENDOJ) y cuyo buscador ofrece, a mi juicio, mejores resultados que el propio del CENDOJ ${ }^{5}$.

En suma, se trata de un ejercicio de comparación / contraposición entre Law in the books y Law in action, que pretende transmitir una imagen nítida de cuál es el panorama que el artículo 183 quater CP arroja tanto a nivel académico como a nivel práctico tras casi cinco años de aplicación.

4 Utilizo el plural en esta nota, dado que el laborioso proceso de búsqueda de las resoluciones y de comprobación de su interés de cara a la realización de este trabajo lo he llevado a cabo con la inestimable colaboración de Darío Pérez Bergantiños, becario de colaboración en mi Departamento durante el curso 2018/2019.

5 En el elenco que incluyo de las sentencias, aparece la referencia en la base de datos Tirant on line, de modo que, si el lector utiliza dicha clave, encuentra inmediatamente en dicha base de datos la sentencia en cuestión. No obstante, lógicamente, podrá encontrarlas igualmente en la propia base de datos del CENDOJ. 


\section{Law in the books: la interpretación doctrinal del art. 183 quarter CP.}

El precepto aquí estudiado reza así:

"El consentimiento libre del menor de dieciséis años excluirá la responsabilidad penal por los delitos previstos en este Capítulo, cuando el autor sea una persona próxima al menor por edad y grado de desarrollo o madurez".

Más allá de la opinión que pueda merecer desde el punto de vista político-criminal la elevación de la edad de consentimiento de los 13 a los 16 años operada por la Ley Orgánica $1 / 2015^{6}$, lo cierto es que, como comentaba antes, una cláusula como la contenida en el artículo 183 quater $\mathrm{CP}$ era necesaria, para no enviar a la ilegalidad penal todas las (ciertamente, no inusuales) relaciones sexuales de los

6 En sentido crítico, vid., entre otros, GONZÁlEZ AGUDELO, G.: "Consecuencias jurídicas y político - criminales de la elevación de la edad del consentimiento sexual en los derechos sexuales y de salud sexual y reproductiva del menor de edad", en Revista electrónica de Ciencia penal y Criminología, número 18-15, 2016, pp. 7 y ss., y, ampliamente, RAMOS VÁZQUEZ, J. A.: Política criminal, cultura y abuso sexual de menores: un estudio sobre los artículos 183 y siguientes del Código penal, Valencia, 2016, pp. 178 y ss. Lo que sí está claro, como bien destaca CUERDA ARNAU, es que la elevación de edad se ha llevado a cabo legislativamente sin el más mínimo apoyo de los datos empíricos. Así, señala dicha autora, "El legislador se refiere sin citarlos a informes (?) o al común conocimiento (!), según los cuales la edad media en que se mantienen relaciones sexuales entre nuestros jóvenes se sitúa alrededor de los dieciséis años. Un legislador responsable debiera haber certificado el dato y conocer con más detalle las actitudes y pautas sexuales de nuestros adolescentes, cerciorándose del porcentaje de jóvenes que se inician a esa edad antes de decidir si era preciso elevarlo tanto y si tampoco en este aspecto existían otras alternativas, conclusión, por cierto, que la Memoria de impacto rechaza con carácter general" (CUERDA ARN$\mathrm{AU}, \mathrm{M}^{\mathrm{a}}$. L.: "Irracionalidad y ausencia de evaluación legislativa en las reformas de los delitos sexuales contra menores", en Revista electrónica de Ciencia penal y Criminología, número 10-09, 2017, p. 36).

En cambio, se muestra favorable a dicha elevación CABRERA MARTÍN, M.: La victimización sexual de menores en el Código penal español $y$ en la política criminal internacional, Madrid, 2019, pp. 164 y ss. 
adolescentes que aún no han cumplido dicha edad. Así lo reconoce unánimemente la doctrina ${ }^{7}$, si bien siempre de modo matizado, indicando que es "necesaria pero defectuosa en su enunciado" $\mathrm{O}$ "necesaria pero insuficiente".

A esos defectos e insuficiencias, detectados por la doctrina desde el primer momento, se dedica este apartado.

\section{1. ¿En concepto de qué se excluye la responsabilidad penal?}

El primer interrogante que surge de la lectura del artículo 183 quater CP es la naturaleza jurídica de la exención prevista en él, siendo casi unánime la posición doctrinal que la considera una causa de atipicidad de la conducta ${ }^{10}$, si bien es cierto, como señala TAMARIT SUMALLA, que "su redacción parece sugerir que nos hallamos ante una causa de justificación"11.

7 Y también la Fiscalía General del Estado en su Circular 1/2017 antes mencionada (p. 7).

8 ORTS BERENGUER, E.: "Delitos contra la libertad e indemnidad sexuales (II)", en GONZÁLEZ CUSSAC, J. L. (coord.): Derecho penal. Parte especial, $6^{\text {a }}$ edición, Valencia, 2019, p. 239.

9 BOIX REIG, J.: "Delitos contra la libertad e indemnidad sexuales (IV)", en BOIX REIG, J. (coord.): Derecho penal. Parte especial, $2^{\mathrm{a}}$ edición, Madrid, 2016, p. 403.

10 Así, entre otros, CANCIO MELIÁ, M.: "Delitos contra la libertad e indemnidad sexuales", en AA.VV., Memento práctico Francis Lefebvre. Penal. 2018, Madrid, 2018, p. 1054; BOLDOVA PASAMAR, M. A.: "Delitos contra la libertad e indemnidad sexuales (I), en ROMEO CASABONA, C. M. / SOLA RECHE, E. / BOLDOVA PASAMAR, M. A. (coords.), Derecho penal. Parte especial, Granada, 2016, p. 209; BOIX REIG, J.: "Delitos contra la libertad e indemnidad sexuales (IV)", cit., p. 404; TAMARIT SUMALLA, J. Ma .: "Delitos contra la indemnidad sexual de menores", en QUINTERO OLIVARES, G. (dir.), Comentario a la reforma penal de 2015, Cizur Menor, 2015, p. 425; GÓMEZ TOMILLO, M.: "Artículo 183 quater", en GÓMEZ TOMILLO, M. (dir.), Comentarios prácticos al Código penal, Tomo II, Cizur Menor, 2015, p. 535, CABRERA MARTÍN, La victimización sexual de menores en el Código penal español, cit., pp. 169 - 170 o GARCÍA ÁLVAREZ, P., "La nueva regulación de los delitos contra la libertad e indemnidad sexual 
Parece lógico y coherente concluir, con la doctrina ampliamente mayoritaria, que, en efecto, se trata de una causa de atipicidad de la conducta, pues considerarla una mera "excusa absolutoria" (como hacen MAÑAS DE ORDU$\tilde{N A}^{12}$ o SUÁREZ-MIRA RODRÍGUEZ ${ }^{13}$ ) plantearía muy notables distorsiones en lo que a las conductas de participación se refiere.

Es decir, si se entiende, como hacen dichos autores, que se trata de una excusa absolutoria (de una "causa personal de exclusión de la pena", por utilizar una terminología más actual y menos confusa), eso supondría que el hecho seguiría siendo antijurídico, por lo que el consentimiento del menor de 16 años eximiría sólo al otro interviniente en el acto sexual y no a eventuales partícipes en el hecho. Esto llevaría a la extraña paradoja de que, por ejemplo, una persona (que podría ser, a su vez, menor de edad) que indujese a un menor de 16 años a tener relaciones sexuales con otro menor sería castigado como tal inductor a un delito de abuso del art. 183 , mientras que quien materialmente lleva a cabo los actos sexuales a los que hace referencia este último precepto podría acogerse a dicha (a mi juicio, sedicente) excusa absolutoria.

tras la reforma operada en el Código penal por la LO 1/2015, de 30 de marzo", en Cuadernos penales José María Lidón, número 12, 2016, p. 281.

11 TAMARIT SUMALLA, J. M".: "Artículo 183 quater", en QUINTERO OLIVARES, G., Comentarios al Código penal español, $7^{\mathrm{a}}$ edición, Cizur Menor, 2016, p. 1332. La considera, efectivamente, una causa de justificación ESCOBAR JIMÉNEZ, R.: "Delitos contra la libertad e indemnidad sexuales", en DEL MORAL GARCÍA, A. (dir.), Código penal: comentarios y jurisprudencia, $4^{\mathrm{a}}$ ed., Tomo I, Granada, 2018, p. 1066.

12 MAÑAS DE ORDUÑA, A.: "Delitos contra la libertad e indemnidad sexuales", en ZÁRATE CONDE, A. (coord.), Derecho penal. Parte especial, 2a edición, Madrid, 2018, p. 195.

13 SUÁREZ-MIRA RODRÍGUEZ, C.: "Tema 32", en SUÁREZ-MIRA RODRÍGUEZ, C. (dir.), Manual de Derecho penal. Parte especial, $7^{\mathrm{a}}$ edición, Cizur Menor, 2018, p. 249. 
Resulta, por consiguiente, más correcto, tanto político-criminalmente como desde la perspectiva de los bienes jurídicos en juego y de la interpretación sistemática de los arts. 183 y siguientes del Código penal, considerar que cualquier conducta de participación en unos actos sexuales que caigan bajo el ámbito de aplicación del art. 183 quater $\mathrm{CP}$ es totalmente impune ${ }^{14}$.

\section{Julieta?}

2. 2. ¿A qué delitos es aplicable la cláusula Romeo y

La segunda cuestión problemática que suscita nuestra cláusula Romeo y Julieta es en cuáles de los "delitos previstos en este Capítulo" (el II bis del Título VIII del Libro II del Código penal, que es en el que se integra el art. 183 quater) se puede alegar dicha cláusula.

Parece lógico pensar que dicha previsión no pueda alcanzar a las agresiones sexuales (previstas en el art. 183.2), en la medida en que la violencia o intimidación que las caracteriza es incompatible con el consentimiento libre que ha de prestar el menor ${ }^{15}$. También parece evidente que el legislador está pensando, fundamentalmente, en el art. 183.1, es decir, en supuestos en los que hay una realización de actos de carácter sexual con el menor de 16 años. Pero, ¿qué sucede con los arts. 183 bis y ter?

La respuesta respecto del primero de dichos artículos, que recoge la conducta de determinar a un menor de dieciséis

14 En esta línea, CANCIO MELIÁ, "Delitos contra la libertad e indemnidad sexuales", cit., p. 1055.

15 En esta línea, MORILLAS FERNÁNDEZ, D. L.: "Los delitos contra la libertad e indemnidad sexuales", en MORILLAS CUEVA, L: (dir.), Estudios sobre el Código penal reformado (Leyes Orgánicas 1/2015 y 2/2015), Madrid, 2015, pp. 465 y ss.; ORTS BERENGUER, "Delitos contra la libertad e indemnidad sexuales (II)", cit., p. 239. Sobre el caso específico de las relaciones sexuales sadomasoquistas, cfr. MORILLAS FERNÁNDEZ, "Los delitos contra la libertad e indemnidad sexuales", cit., pp. 465 y s. con GARCÍA ÁLVAREZ, "La nueva regulación de los delitos contra la libertad e indemnidad sexual", cit., pp. 282 y s. 
años a participar en un comportamiento de naturaleza sexual o hacerle presenciar actos de carácter sexual, aunque el autor no participe en ellos, depende, lógicamente, de cómo interpretemos "determinar" y "hacer presenciar".

Dado que excedería del objeto de este trabajo entrar en dicha cuestión, sumamente discutida, me limito a señalar que, a mi juicio, aun con ciertas dudas ${ }^{16}$, ni "determinar" ni "hacer presenciar" suponen conducta alguna de intimidación, coacción o presión, de suerte que considero que perfectamente pueden quedar eximidas por el consentimiento del menor de 16 años, en los términos expresados por el art. 183 quater $\mathrm{CP}^{17}$.

En cuanto al art. 183 ter. $1 \mathrm{CP}$, parece claro que no podrá aplicarse la cláusula Romeo y Julieta "cuando el acercamiento se obtenga mediante coacción, intimidación o engaño" (último inciso de dicho apartado), pero sí cuando no se haya acudido a dichos medios comisivos. En cambio, en mi opinión, no podrá alegarse el art. 183 quater para eximir las conductas del art. 183 ter. $2 \mathrm{CP}$, pues el "embaucamiento" al que hace referencia este último precepto es incompatible con el "consentimiento libre" al que hace referencia el primero ${ }^{18}$.

16 Compartidas, por ejemplo, por ESCOBAR JIMÉNEZ, "Delitos contra la libertad e indemnidad sexuales", cit., p. 1067, quien afirma que "el verbo rector "determine" puede difuminar el libre consentimiento del menor, del que parte el art. 183 quater".

17 En igual sentido, MORILLAS FERNÁNDEZ, "Los delitos contra la libertad e indemnidad sexuales", cit., p. 466.

18 De la misma opinión, SUÁREZ-MIRA RODRÍGUEZ, "Tema 32", cit., p. 248 o ESCOBAR JIMÉNEZ, "Delitos contra la libertad e indemnidad sexuales", cit., p. 1067. En contra, TAMARIT SUMALLA, quien indica que "debe interpretarse la cláusula que aquí se comenta según las exigencias propias de una interpretación teleológica y sistemática, lo cual debe llevar a entender que, si se establece la exención en los casos más graves de abuso sexual, con mayor razón procederá en delitos como los del art. 183 ter, con naturaleza de actos preparatorios, respecto a los cuales existe cierta normalización social de estos comportamientos producidos entre personas de edad próxima, sin un riesgo de afectación a su libertad o indemnidad sexual que sea equiparable a las conductas 
Por su parte, la Circular 1/2017 de la Fiscalía General del Estado llega a idénticas conclusiones, señalando que "el capítulo al que la norma se proyecta es el II bis, que abarca acciones típicas en las que concurre violencia, intimidación o prevalimiento. Lógicamente estas acciones en ningún caso pueden entenderse consensuadas y por tanto no cabrá ante ellas aplicar la previsión del art. 183 quater CP. En relación con el delito del art. 183 ter CP apartado primero (el doctrinalmente denominado grooming) podrá teóricamente apreciarse esta cláusula en relación con el tipo básico, pero no respecto del agravado, que requiere la concurrencia de violencia, intimidación o engaño. Tampoco podrá apreciarse la exención respecto del delito del apartado segundo del art. 183 ter CP, por ser incompatible el "consentimiento libre" que se exige en el 183 quater con el "embaucamiento" propio del doctrinalmente denominado sexting" 19 .

Dicho lo anterior, lo que sí se critica unánimemente en la doctrina es, precisamente, que el art. 183 quater CP sea aplicable sólo a los delitos previstos en el Capítulo del CP en el que se encuentra contenido y no se extienda, en consecuencia, a "conductas fuera del referido capítulo, de menor carga lesiva, como las de los arts. 185 y $186 " 20$.

En efecto, la doctrina no ha podido menos que denunciar el absurdo valorativo que supone que un menor de 16 años pueda consentir válidamente actos sexuales (contenido del art. $183 \mathrm{CP}$ ), pero no actos constitutivos de exhibicionismo (art. $185 \mathrm{CP}$ ), visionado de pornografía (art. $186 \mathrm{CP}$ ) o, incluso, envío o posesión de pornografía de otros menores ${ }^{21}$ (art. $189 \mathrm{CP}$ ).

en las que existe asimetría de edad" (TAMARIT SUMALLA, "Artículo 183 quater", cit., p. 1332).

19 FISCALÍA GENERAL DEL ESTADO, Circular 1/2017, cit., p. 11.

20 ORTS BERENGUER, "Delitos contra la libertad e indemnidad sexuales (II)", cit., p. 239. En igual sentido, GARCÍA ÁLVAREZ, "La nueva regulación de los delitos contra la libertad e indemnidad sexual”, cit., p. 283.

21 En igual sentido, MORILLAS FERNÁNDEZ, "Los delitos contra la libertad e indemnidad sexuales", cit., p. 466. 
Respecto de esto último, no está de más recordar que ya la Circular 9/2011 de 16 de noviembre, sobre criterios para la unidad de actuación especializada del Ministerio Fiscal en materia de reforma de menores señalaba que "cuando no hay asimetría de edad entre el menor poseedor de pornografía y los menores representados en el material, no puede decirse que exista una lesión al bien jurídico protegido, ni propiamente, una conducta pedófila. Por tanto, antes de formular alegaciones contra un menor por delito de pornografía infantil deben sopesarse con extremo cuidado las consecuencias y los potenciales beneficios, huyendo de automatismos $\mathrm{y}$ teniendo presente que los efectos estigmatizadores pueden ser devastadores (...). Estas pautas también son extensibles (...) al exhibicionismo (art. $185 \mathrm{CP}$ ) y a la exhibición de pornografía a menores (art. $186 \mathrm{CP}$ )"22. Esta última postura me parece más que compartible.

\section{3. ¿A qué tramos de edad es aplicable la cláusula?}

La tercera gran cuestión abierta al debate doctrinal es la referida al inciso "una persona próxima al menor por edad", discutiéndose sobre cuándo existe dicha proximidad y sobre si cualquier edad es susceptible de entrar en juego o, por el contrario, debe interpretarse que existen límites superiores / inferiores de edad para poder aplicar la cláusula.

Respecto a esto último, por más que MAÑAS DE ORDUÑA indique que existe "cierto acuerdo doctrinal en considerar que podrá aplicarse la excusa absolutoria ${ }^{23}$ cuando la víctima sea menor de 16 años y el sujeto activo menor

22 FISCALÍA GENERAL DEL ESTADO, Circular 9/2011 de 16 de noviembre, sobre criterios para la unidad de actuación especializada del Ministerio Fiscal en materia de reforma de menores, p. 18. Disponible on line en la dirección web: https://www.boe.es/buscar/abrir_fiscalia. php?id=FIS-C-2011-00009.pdf -última consulta: 24 de julio de 2020-.

23 Recordemos que este autor considera que el art. 183 quater establece una excusa absolutoria. 
de edad, pero nunca cuando sea mayor de edad"24, lo cierto es que, en lo que se me alcanza, no hay nadie en la doctrina que sostenga semejante interpretación. Al contrario, varios autores han planteado esa hipótesis expresamente y todos ellos han concluido (con buen criterio, a mi juicio, pues, para empezar, la cláusula no prevé ninguna limitación que afecte sólo a menores de edad) que una persona mayor de edad puede perfectamente acogerse a la exención que le brinda el consentimiento libre del menor de 16 años ${ }^{25}$.

En suma, concuerdo con MORILLAS FERNÁNDEZ cuando señala que la mayoría de edad no implica de por sí la inaplicabilidad del art. 183 quater porque: "i) esta opción no cabe deducirla expresamente de la cláusula; ii) con la Política Criminal restrictiva del legislador, si su espíritu hubiese sido ése, lo hubiera referido expresamente; y iii) al no optar por un sistema de edades cerradas, los dieciocho años se encuentran en una franja donde pueden encontrarse similitudes de madurez y desarrollo con los menores, por lo que no debe establecerse una presunción en contrario, sino que debe acreditarse su ausencia"26.

Lo que sí es discutido es si la cláusula alcanza a cualquier menor de 16 años o si, por el contrario, existe un límite mínimo de edad para que el consentimiento libre al que hace referencia el art. 183 quater CP pueda surtir efecto.

Esto último es sostenido por GARCÍA ÁLVAREZ, quien señala que es "excesivo que se deje la puerta abierta a la relevancia del consentimiento de todo menor de dieciséis años. Entiendo que, en este contexto, el legislador debería

24 MAÑAS DE ORDUÑA, "Delitos contra la libertad e indemnidad sexuales", cit., p. 196.

25 Así, ORTS BERENGUER, "Delitos contra la libertad e indemnidad sexuales (II)", cit., p. 239; GÓMEZ TOMILLO, "Artículo 183 quater", cit., p. 536, SUÁREZ-MIRA RODRÍGUEZ, “Tema 32”, p. 248.

26 MORILLAS FERNÁNDEZ, "Los delitos contra la libertad e indemnidad sexuales", cit., p. 464. 
haber blindado a los menores de determinadas edades y que su consentimiento no pudiera entenderse como válido en supuesto alguno, por ejemplo, hasta los trece años"27.

Lo contrario, es decir, que no existe ningún límite inferior a partir del cual el consentimiento libremente prestado por el menor carecería de eficacia eximente, es sostenido, por ejemplo, por GONZÁLEZ AGUDELO, quien señala que es posible "un consentimiento válido, sin tope inferior de edad, si se cumplen los requisitos" 28 .

Esta última opinión es, a mi juicio, más coherente con el conjunto de la cláusula, la cual ni excluye expresamente edad alguna, ni-en mi opinión- puede fácilmente conciliarse con la existencia de un supuesto límite infranqueable puramente cronológico. En efecto, la amplitud de la cláusula y el hecho de que, en ningún supuesto, la mera (diferencia de) edad sea condición suficiente para la exención prevista en el art. 183 quater $\mathrm{CP}$ parecen abonar la tesis de que no existe ninguna edad por debajo de la cual aquélla no resulte aplicable.

En igual sentido, la Circular 1/2017 de la Fiscalía General del Estado, como veremos inmediatamente, no excluye la posibilidad de aplicar la cláusula a menores de 13 años, siempre que sean púberes ${ }^{29}$, criterio éste de no establecer un límite mínimo infranqueable para la aplicación del art. 183 quater $\mathrm{CP}$ que, insisto, me parece totalmente correcto.

27 GARCÍA ÁLVAREZ, "La nueva regulación de los delitos contra la libertad e indemnidad sexual", cit., p. 283. En igual sentido, proponiendo también la misma edad de trece años como "barrera infraqueable", MORILLAS FERNÁNDEZ, "Los delitos contra la libertad e indemnidad sexuales", cit., p. 464.

28 GONZÁLEZ AGUDELO, "Consecuencias jurídicas y político - criminales", cit., p. 8.

29 FISCALÍA GENERAL DEL ESTADO, Circular 1/2017, cit., p. 9. 


\section{4. ¿Qué edades son próximas entre sí?}

Como muy bien apuntó ya en su día RAGUÉS I VALLÉS, "qué se entiende por "proximidad" a efectos de este delito promete ser una compleja cuestión interpretativa que el legislador ha dejado en mano de los tribunales"30. Y lo cierto es que, como veremos en breve, efectivamente, los tribunales han tenido que pronunciarse reiteradamente sobre esta cuestión que el art. 183 quater $\mathrm{CP}$ ha dejado abierta.

Este hecho, es decir, que la cláusula Romeo y Julieta no haya incluido ningún parámetro de cercanía entre las edades -como sí hacen otros Estados- ha sido, por lo general, saludado como un acierto por parte de la doctrina. Así, por ejemplo, CABRERA MARTÍN indica que "el establecimiento de una diferencia fija y única de edades, ya sea esta de tres, cinco, ocho o diez años, probablemente ocasionaría más problemas que la opción más genérica finalmente elegida, por cuanto dichas edades sólo resultarían adecuadas para dar solución a algunos casos y atarían las manos al Juez para resolver de una manera razonable otros"31. En una línea muy similar, MORILLAS FERNÁNDEZ señala que "establecer cuantificaciones de edad apriorísticas (...) limitaría sobremanera las posibilidades de interactuación en este ámbito, encorsetando las relaciones hacia unos parámetros definidos y neutros" 32 .

Por el contrario, GÓMEZ TOMILLO señala, críticamente, que "al final nos encontraremos con un acuerdo de pleno no jurisdiccional del Tribunal Supremo que ponga una

30 RAGUÉS I VALLÉS, R.: "Delitos contra la libertad e indemnidad sexuales”, en SILVA SÁNCHEZ, J. Ma (dir.) / RAGUÉS I VALLÉS, R. (coord.), Lecciones de Derecho penal. Parte especial, cuarta edición, Barcelona, 2015, p. 141.

31 CABRERA MARTÍN, La victimización sexual de menores en el Código penal español, cit., p. 167. Destacado en cursiva en el original.

32 MORILLAS FERNÁNDEZ, "Los delitos contra la libertad e indemnidad sexuales", cit., p. 462. 
edad máxima, por ejemplo, los 18 años, y una distancia entre sujeto activo y sujeto pasivo. Y para que lo decida así el Tribunal Supremo, bien podría haberlo hecho el legislador, que es a quien le corresponde" ${ }^{33}$.

Dicho Acuerdo de pleno aún no existe, pero sí que es cierto que la Circular de la Fiscalía General del Estado $1 / 2017$ ha planteado directamente una propuesta de graduación de edades a los efectos de la cláusula Romeo y Julieta. Dice así la Circular:

"En lo que concierne al menor protegido, puede trazarse el siguiente esquema:

- Impúberes. En ellos aún no se ha producido el proceso de cambios físicos en el cual el cuerpo del niño o niña adquiere la capacidad de la reproducción sexual. No puede establecerse una edad fija para delimitar la infancia de la pubertad pues el inicio del proceso de cambios varía de una persona a otra, dependiendo de diversos factores, entre ellos el sexo. Se trata propiamente de niños y no de adolescentes y respecto de ellos su protección debe ser absoluta (...).

-El segundo nivel de protección abarcaría desde el inicio de la pubertad hasta los 13 años inclusive, siempre que dicho proceso fisiológico haya comenzado antes de dicha edad. En esta franja, la protección del menor es intensa por encontrarse en la primera fase de la adolescencia (...). En relación con la edad del autor, el límite máximo respondería a la mayoría de edad, esto es, hasta cumplir los 18 años, por lo que -con carácter general- podría dar cobertura únicamente a las relaciones entre menores.

-14 y 15 años, ambos inclusive. La protección debe permitir una diferencia de edad que abarque a los jóvenes hasta 20 años inclusive, moderándose en atención al segundo parámetro (grado de desarrollo o madurez). Excepcional-

33 GÓMEZ TOMILLO, “Artículo 183 quater”, cit., p. 535. 
mente podrían comprenderse los jóvenes de hasta 24 años inclusive, atendiendo al grado de desarrollo o madurez tanto del menor como del joven que mantienen el contacto sexual.

Esta pauta debe entenderse de carácter orientador" ${ }^{34}$.

Como puede apreciarse, los parámetros fijados por la Fiscalía General del Estado son ciertamente generosos, probablemente porque los Fiscales, pieza clave en el engranaje de protección de la infancia-de un lado-y del Derecho penal de menores -de otro- son perfectamente conscientes de que la proximidad de edad prevista en el art. 183 quater CP debe ser entendida del modo más amplio posible, para evitar consecuencias político-criminalmente insatisfactorias ${ }^{35}$.

Por mi parte, partiendo de que el legislador quiso expresamente esta solución indefinida ${ }^{36} \mathrm{y}$ de que hay buenas razones que la avalan -en especial el hecho de que resulta difícil precisar una diferencia de edad que resulte incontrovertida como indicio de una relación abusiva y que, a su vez, no sea demasiado amplia-, lo cierto es que las dosis de inseguridad jurídica que supone podrían hacer preferible otra solución.

34 FISCALÍA GENERAL DEL ESTADO, Circular 1/2017, cit., p. 5.

35 Ello no obstante, como bien señala CANCIO MELIÁ, el criterio de la Fiscalía puede no ser suficiente "en un ordenamiento procesal como el español, que conoce el ejercicio de la acción penal a título de acusación particular o popular -a diferencia de los países de nuestro entorno, en los que compete, en principio, al Ministerio Fiscal ejercerla, constituyéndose el criterio de la fiscalía en un filtro para eliminar casos en los que no parece adecuado proceder-" (CANCIO MELIÁ, "Delitos contra la libertad e indemnidad sexuales", cit., p. 1055).

36 Pues se rechazó expresamente la enmienda presentada por el Grupo parlamentario Unión Progreso y Democracia en el sentido de establecer una diferencia de edad tasada legalmente. Vid. Boletín Oficial de las Cortes Generales, $n^{\circ} 66-2$, de 10 de diciembre de 2014, enmienda $n^{\circ}$ 561, p. 369 (disponible en http://www.congreso.es/public_oficiales/L10/ CONG/BOCG/A/BOCG-10-A-66-2.PDF -fecha de última consulta: 24 de julio de 2020-). 
Y ésta, en mi opinión, sería la de establecer una diferencia de edad holgada (quizás cinco años ${ }^{37}$ ) entre las personas involucradas en los hechos y añadirle, como opción alternativa y no cumulativa, la posibilidad de que, aun superando dicha diferencia de edad, se pueda igualmente aplicar la exención de pena a quien tenga un grado de madurez similar a la del menor o la menor. Es decir, si ha de existir una edad de consentimiento tan elevada, con el indudable impacto que esto tiene en la criminalización de la vida sexual adolescente, que al menos sean alternativos y no cumulativos los dos grandes criterios existentes para determinar la condición no abusiva de dichas relaciones ${ }^{38}$ y que el primero de ellos -el cronológico- esté tasado, para no añadir más incerteza a la que ya proporciona el segundo -el de la madurez-, como señalaré inmediatamente.

\section{5. ¿Qué grados de desarrollo o madurez son próxi- mos entre sí?}

De todas las previsiones del art. 183 quater CP, es ésta, junto a la limitación de su aplicación a los artículos del Capítulo en que se haya contenido, la que mayores críticas ha suscitado.

Sin duda, para la doctrina penal, resulta difícil de admitir que la punición o no de una relación sexual entre un

37 Misma cifra y mismas dudas que las mostradas por MORILLAS FERNÁNDEZ, "Los delitos contra la libertad e indemnidad sexuales", cit., p. 462.

38 Que los criterios expresados en el art. 183 quater son cumulativos es algo que se deduce directa y palmariamente del texto de dicho precepto (y así -como no podía ser de otro modo- lo concibe la doctrina: GÓMEZ TOMILLO, "Artículo 183 quater", cit., p. 535; SUÁREZ-MIRA RODRÍGUEZ, "Tema 32", cit., p. 248; CANCIO MELIÁ, "Delitos contra la libertad e indemnidad sexuales", cit., p. 1055; ESCOBAR JIMÉNEZ, "Delitos contra la libertad e indemnidad sexuales", cit., p. 1066 o MAÑAS DE ORDUÑA, "Delitos contra la libertad e indemnidad sexuales", cit., p. 196, entre otros). Señalo esto anticipadamente porque, como indicaré en el apartado correspondiente al análisis jurisprudencial, existe al menos una sentencia que lo niega... 
menor de 16 años y otra persona pueda estar condicionada a un requisito tan vago como el de la similitud de desarrollo o de madurez.

Ante todo, parece que "desarrollo", separado de "madurez", apunta a que la primera mención venga referida al aspecto puramente físico, mientras que la segunda se refiera al "estado en que se encuentre su proceso de progreso cognitivo y emocional" 39 . De otra opinión, en cambio, se muestra GÓMEZ TOMILLO, quien considera que "debería entenderse que estamos más ante una cláusula de estilo que otra cosa, en la medida en que el nivel de desarrollo físico no debería ser un dato a considerar como decisivo cuando de proteger la indemnidad sexual del menor se trata" ${ }^{40}$.

Sea como fuere, lo cierto es que, tanto juntas como por separado, son dos nociones difícilmente asibles: en efecto, incluso si, como propuso en su día una autora, cuando la actual regulación era sólo un proyecto, hemos de entender esas nociones en el sentido de una "sintonía de expectativas, intereses y emociones" y una igualdad en la vivencia de la experiencia sexual mantenida ${ }^{41}$, la inconcreción de todo ello y la necesidad de indagar, en el seno de un proceso penal, en aspectos íntimos de los implicados (uno de ellos necesariamente

39 ESCOBAR JIMÉNEZ, "Delitos contra la libertad e indemnidad sexuales", cit., p. 1066, quien, acto seguido critica que el legislador haya optado por una "clave alternativa" en los requisitos, en vez de exigir ambos (desarrollo y madurez) conjuntamente.

40 GÓMEZ TOMILLO, “Artículo 183 quater", cit., p. 536.

41 ROPERO CARRASCO, J.: "Reformas penales y política criminal en la protección de la indemnidad sexual de los menores. El proyecto de 2013”, en Estudios penales y criminológicos, número 34, 2014, p. 269. En similar sentido, JAÉN VALLEJO / PERRINO PÉREZ indican que "la asimetría de edad hace imposible una actividad sexual común, en la medida en que los participantes tendrán experiencias, grado de madurez bio-psicológica y expectativas muy diferentes" (JAÉN VALLEJO, M. / PERRINO PÉREZ, A. L.: La reforma penal de 2015: análisis de las principales reformas introducidas en el Código penal por las Leyes Orgánicas 1 y 2/2015, de 30 de marzo, Madrid, 2015, p. 94). 
menor de 16 años) me resultan muy perturbadoras, sobre todo por lo estigmatizador que puede ser dicho análisis ${ }^{42}$. Sobre ello abundaré en las conclusiones de este trabajo, una vez explique qué está sucediendo en la praxis jurisprudencial.

Es más, al no existir absolutamente ningún parámetro que permita cuantificar la similitud de desarrollo y madurez entre dos personas, el art. 183 quater $\mathrm{CP}$ es terreno abonado para que el juzgador (o, como mínimo, el instructor) pueda, de un modo u otro, verter sus propias percepciones sobre la vida afectivo-sexual de los menores concretos (o de los menores en abstracto), como de hecho veremos que sucede en la parte dedicada en este trabajo a la aplicación jurisprudencial de la cláusula.

En este sentido, como señala GÓMEZ TOMILLO, estamos, en resumidas cuentas, ante una "cláusula muy abierta, difícilmente compatible con la seguridad jurídica y que va a permitir pronunciamientos judiciales muy diversos según las convicciones, educación o prejuicios de cada juzgador"43.

Muestra de ello podría ser, por ejemplo, el estudio llevado a cabo por REITZ-KRUEGER et al., en el que se pone de manifiesto que existen notabilísimas diferencias entre la percepción que los jóvenes (en concreto, personas de 18 a 24 años) tienen sobre la madurez de los adolescentes para consentir relaciones sexuales con personas mayores que ellos y la percepción que sobre ello tienen los adultos con hijos adolescentes $^{44}$.

Sea como fuere, lo cierto es que, más allá de la porosidad de los conceptos "desarrollo" y "madurez", capaces

42 En igual sentido, GONZÁLEZ AGUDELO, "Consecuencias jurídicas y político - criminales", cit., p. 8 .

43 GÓMEZ TOMILLO, "Artículo 183 quater", cit., p. 536.

44 REITZ-KRUEGER, C. L. / WARNER, T. C. / NEWSHAM, R. L. I REPUCCI, N. D.: "Who's to blame? Perceptions of adolescents' maturity and responsibility in sexual relationships with an older partner", en Psychology, public policy and Law, número 22 (1), 2016, pp. 105 y ss. 
de absorber preconcepciones por parte de los operadores jurídicos, el art. 183 quater CP habilita a éstos para poder alcanzar una solución caso a caso lo que, en determinadas situaciones, puede resultar político-criminalmente ajustado $\mathrm{y}$, en otras, puede perpetuar un modo limitador y tradicional de entender las relaciones sexuales. La misma ambivalencia y la misma incertidumbre, en suma, que rezuma la cláusula Romeo y Julieta del art. 183 quater CP en su conjunto y que han tenido que ser despejadas por los tribunales en una, a su vez, ambivalente e incierta jurisprudencia, la cual centrará la segunda parte de este trabajo.

\section{3. (Toda la) jurisprudencia en materia: respuestas y nuevas incógnitas sobre el art. 183 quater CP.}

Como señalaba al comienzo de este trabajo, tras el repaso a las posiciones doctrinales existentes sobre cómo conviene interpretar nuestra cláusula Romeo y Julieta, y sus muchas cuestiones problemáticas, llega el turno del análisis de la heteróclita jurisprudencia recaída en materia.

Dadas las limitaciones intrínsecas, que el lector conocerá sobradamente, de la búsqueda a través de bases de datos, no puedo garantizar que constituyan el $100 \%$ de las sentencias recaídas en materia, razón por la que pongo entre paréntesis que se trate, efectivamente, de todas. Desde luego, se ve lastrado mi análisis -de un lado-por el hecho de que las sentencias de la jurisdicción de menores no suelen ser accesibles a través de las bases de datos y -de otro- por el hecho de que, quizás, haya habido muchos sobreseimientos y archivos de procesos, precisamente a causa de la aplicación del art. 183 quater $\mathrm{CP}$, de los que no puedo llegar a tener noticia. En todo caso, la muestra recogida incluye todas las sentencias del Tribunal Supremo y decenas de sentencias de la llamada "jurisprudencia menor", de modo que la considero suficientemente expresiva de la situación jurisprudencial tras los primeros cinco años de vigencia de la cláusula. 
En efecto, tras descartar aquellas sentencias en las que la aplicación de la cláusula era tan improcedente que no se entraba en su valoración (por ejemplo, por haberse alegado en supuestos que, a la postre, fueron calificados como agresiones sexuales ${ }^{45}$ ), la muestra sobre la que he trabajado es de un total de 51 resoluciones (6 del Tribunal Supremo y 45 de otros órganos jurisdiccionales), cuyo elenco, con mención de su referencia en la base de datos, podrá encontrar el lector al final del trabajo.

De esas 51 resoluciones, sólo 13 supusieron la absolución de quien alegó a su favor el art. 183 quater, lo que supone una tasa de éxito muy baja (aunque, ciertamente, hay bastantes supuestos en que se pide la aplicación de la cláusula sin demasiada base). En 45 de los casos en que se alegó el consentimiento del menor o la menor de 16 años, las "víctimas" ${ }^{\prime 6}$ eran mujeres y en los restantes 6 se trataba de menores varones. Por último, como dato general, indicar que sólo en uno de los 51 casos sometidos a la decisión judicial la autora era una mujer ${ }^{47}$.

45 Por ejemplo, entre otras, la Sentencia Audiencia Provincial de Guadalajara de 22 de febrero de 2019, en la que no se entra a valorar la aplicación del art. 183 quater por haberse declarados probados, entre otros, los siguientes hechos: "el acusado acudió al domicilio de la menor [de 12 años de edad], y aprovechando que estaba sola en el salón y a pesar de que ésta intentó alejarse de él al verle, la siguió y la cogió del brazo, metiéndola en el baño de la planta primera y, una vez allí, echó por dentro el pestillo de la puerta para que no se fuera, y colocó a la menor de espaldas a él y de cara al lavabo, agarrándola fuertemente para que no se moviera, momento en el que, para satisfacer sus deseos sexuales, le bajó los pantalones y la penetró vaginalmente, tapándole la boca para que no gritara, sintiendo la niña un gran dolor, ejerciendo el acusado más fuerza sobre la menor cuanto más se resistía ésta".

46 Entrecomillo "víctimas" porque, como señalo en el texto, en 13 de las resoluciones se produce la absolución del acusado, de modo que (y ésta es una de las muchas paradojas indicadas en su momento) técnicamente las personas consideradas en su día víctimas pasaron a ser, sin más, menores que habían ejercido libremente su derecho a la libertad sexual...

47 En concreto, se trata de la Sentencia de la Audiencia Provincial de Asturias de 15 de mayo de 2019. 
Dicho todo lo anterior, he planteado este análisis jurisprudencial del siguiente modo: en primer lugar, haré referencia a las (más bien escasas) resoluciones del Tribunal Supremo en materia. Acto seguido, analizaré las sentencias de los Tribunales Superiores de Justicia y de las Audiencias Provinciales, subdividiendo su contenido en función de cómo responden a las dudas planteadas por la doctrina y qué cuestiones nuevas plantean.

\subsection{La jurisprudencia del Tribunal Supremo}

Hasta el momento (siempre con la debida precaución respecto a la muestra que he recabado), el Tribunal Supremo se ha pronunciado en seis ocasiones sobre la cláusula Romeo y Julieta ${ }^{48}$ : tres veces mediante sentencia y otras tantas mediante auto.

Comenzando por estos últimos, en dos de ellos se rechaza la pretensión del recurrente de que se le aplique el art. 183 quater CP por la abultadísima diferencia de edad que le separa de la víctima (35 años en un caso $^{49}$ y 55 años en el otro $^{50}$ ) y en el tercero porque la víctima estaba dormida y, por consiguiente, no estaba en condiciones de prestar consentimiento alguno ${ }^{51}$.

En cuanto a las sentencias del Alto Tribunal, en una de ellas ${ }^{52}$ rechaza de plano la aplicación de la cláusula, al triplicar la edad del autor la de la víctima, y en otra menciona la cláusula, pero no porque se haya alegado por el recurrente, sino para enfatizar que la diferencia de edad en dicho

48 Excluyo, en este sentido, su Sentencia de 19 de octubre de 2016, citada en ocasiones por otras sentencias del propio Tribunal Supremo, pero en la que, en realidad, se excluye la responsabilidad penal del acusado por error (art. 14) y no por aplicación del art. 183 quater, que no es alegado por el recurrente.

49 Auto del Tribunal Supremo de 21 de enero de 2016.

50 Auto del Tribunal Supremo de 23 de marzo de 2017.

51 Auto del Tribunal Supremo de 12 de septiembre de 2019.

52 Sentencia del Tribunal Supremo de 14 de octubre de 2019. 
supuesto (20 años el recurrente, 11 la víctima) está "fuera de los límites señalados, para la exclusión de responsabilidad, por la novedosa figura introducida, por la LO 1/2015, en el art. 183 quater del CP"53; por lo que, en realidad, podríamos decir que el Tribunal Supremo sólo ha llegado a pronunciarse sobre el fondo del asunto en una única ocasión.

En dicha sentencia, de 18 de enero de 2017, se estudia el recurso de un condenado, de 20 años de edad en el momento de los hechos, que había tenido una serie de relaciones sexuales con su pareja de aún no 12 años cumplidos, lo que motivó su condena por un delito continuado de abusos sexuales, al no haber aceptado el tribunal a quo la aplicación del art. 183 quater CP. El Tribunal Supremo confirma dicha inaplicabilidad de la cláusula de consentimiento, señalando lo siguiente:

"La diferencia de edad es superior a los ocho años y medio. A ello debe añadirse que se produce entre jóvenes de más de veinte años y niñas que no han alcanzado todavía los doce años cuando sucedieron los hechos, lo que desde luego influye igualmente en el grado de desarrollo y madurez alejándolo de la proximidad mencionada. Por lo tanto, la conclusión de la Sala de instancia no es ni mucho menos irrazonable. También hay que añadir otras circunstancias del caso, especialmente, como aduce el Ministerio Fiscal, que el acusado en el momento de los hechos acababa de finalizar una relación de dos años con una joven de su edad con la que convivía. Se trata pues de tener en cuenta el equilibrio de la pareja atendiendo a las circunstancias legales, es decir, la edad y el espíritu y mentalidad de ambos, debiendo rechazarse los casos de desequilibrio relevantes y notorios desde el punto de vista objetivo, pero también subjetivamente cuando aquél pueda inferirse del contexto en el que tiene lugar

53 Sentencia del Tribunal Supremo de 15 de diciembre de 2016, fundamento jurídico $5^{\circ}$. En puridad, como sabemos, dicho precepto no establece límite alguno cronológico para su eventual aplicación. 
la relación, lo que determina un cuidadoso examen de cada caso" ${ }^{54}$.

Este último párrafo constituye, en este momento, la única indicación del Tribunal Supremo sobre la cláusula Romeo y Julieta, y es reproducido por muchas de las posteriores sentencias de las Audiencias Provinciales ${ }^{55}$, si bien, a mi juicio, resulta un parámetro más bien dúctil.

En efecto, el Alto Tribunal se limita a indicar que una diferencia de edad de 8 años y medio, unido a que la menor esté en fase de incipiente pubertad impiden en este caso la aplicación del art. 183 quater $\mathrm{CP}$, pero que la decisión debe ser individualizada en cada caso concreto, atendiendo, como eje rector, a la idea de equilibrio entre "la edad y el espíritu y mentalidad de ambos". No es poco decir, ni en absoluto errado (pues, sin duda, la idea de equilibrio es un buen epítome del precepto), pero ciertamente no resuelve las muchas cuestiones dudosas que la doctrina ha puesto de relieve (como vimos en el apartado anterior) y que, efectivamente, han tenido que ser despejadas caso a caso, como indicaré acto seguido.

\subsection{La llamada "jurisprudencia menor": estado ac- tual de la interpretación de la cláusula.}

Al igual que en el apartado dedicado a la doctrina, he dividido éste en subapartados interrogativos, en los que expongo las respuestas que a dichas cuestiones ha dado la jurisprudencia de las Audiencias Provinciales y Tribunales Superiores de Justicia.

54 Sentencia del Tribunal Supremo de 18 de enero de 2017, fundamento jurídico $2^{\circ}$.

55 Para ser precisos, un total de 14 sentencias de la llamada "jurisprudencia menor" hacen mención expresa a ese fragmento. 
penal?

\subsection{1. ¿En concepto de qué se excluye la responsabilidad}

Como veíamos antes, se trata de una cuestión en la que la doctrina apenas encuentra fisuras, considerando que nos hallamos ante una causa de atipicidad de la conducta.

Sin embargo, esta posición sólo es explícita en dos sentencias de las Audiencias Provinciales ${ }^{56}$, e implícita en otra ${ }^{57}$. Es decir, sólo en dos sentencia se dice expresamente que el art. 183 quater $\mathrm{CP}$ es una cláusula de atipicidad, y en otra no se indica nada al respecto, pero se absuelve a la madre de ambos intervinientes en la relación sexual (hermanastros entre sí: una menor, el otro mayor de edad) tanto por no haber quedado acreditada su no oposición a dicha relación, cuanto "por el propio hecho de que entienda el Tribunal que resulta aplicable el art. 183 quáter CP" 58 , lo que parece dar a entender que dicho órgano jurisdiccional concibe el mencionado artículo como una cláusula de atipicidad.

El resto de pronunciamientos judiciales en que se hace referencia al interrogante que nos ocupa lo resuelven señalando que estamos ante una "excusa absolutoria" 59 , si bien no está claro, a mi juicio, hasta qué punto se utiliza dicha expresión en su sentido técnico y no como impreciso sinónimo de "eximente".

Me explico: de un lado, en ninguna de las resoluciones en que se utiliza la terminología "excusa absolutoria" se dan

56 En concreto, las sentencias de la Audiencia Provincial de Las Palmas de 6 de febrero de 2019 y de la Audiencia Provincial de Burgos de 7 de febrero de 2019.

57 Me refiero a la sentencia de la Audiencia Provincial de Tenerife de 21 de marzo de 2016.

58 Sentencia de la Audiencia Provincial de Tenerife de 21 de marzo de 2016, fundamento jurídico segundo.

59 Por ejemplo, entre otras, las sentencias de la Audiencia Provincial de Burgos de 3 de julio de 2018 y 3 de abril de 2019, de la Audiencia Provincial de Madrid de 18 de septiembre de 2018, o de la Audiencia Provincial de Badajoz de 17 de julio de 2018. 
mayores explicaciones al respecto, y, de otro, en la única sentencia en que se utiliza dicha terminología y hay partícipes en los hechos (en concreto, unos padres que arreglan un matrimonio entre su hijo, que recién ha cumplido los 18 años, y una chica de $13^{60}$ ), se absuelve al acusado, pero no se imputa a los padres por cooperación necesaria cuando, en puridad, si de verdad se tratase de una excusa absolutoria, como asume el Tribunal, el art. 183 quater CP no tendría ningún efecto eximente sobre aquéllos, al no reunir las cualidades legalmente requeridas para la exclusión de la pena.

Por ello, más allá de la sistemática mención a la naturaleza de "excusa absolutoria" de la cláusula Romeo y Julieta, sería cauto a la hora de afirmar que, de hecho, la jurisprudencia menor considera dicha cláusula una auténtica causa personal de exclusión de la pena y no de atipicidad de la conducta erga omnes (por así decirlo). En todo caso, como con sorna señala la Audiencia Provincial de Las Palmas, habrá que esperar "a que la Sala $2^{\mathrm{a}}$ del TS nos ilumine con su infinita sabiduría" ${ }^{1}$.

\subsection{2. ¿Son los requisitos cumulativos?}

Como señalé en su momento, no sólo la doctrina es unánime en considerar ambos criterios -cronológico y de desarrollo / madurez- como cumulativos, sino que la dicción del precepto parece meridiana en este sentido.

Sin embargo, la sentencia de la Audiencia Provincial de Tenerife de 21 de marzo de 2016 (valorando la relación entre dos hermanastros de 22 y 13 años de edad) señala lo siguiente: "la proximidad por edad a que se refiere el actual art. 183 quáter no puede entenderse referida sin más a la edad cronológica, sino que debe ser puesta en relación con el segundo inciso del precepto, que se refiere al "grado de

60 Sentencia de la Audiencia Provincial de Badajoz de 17 de julio de 2018.

61 Sentencia de la Audiencia Provincial de Las Palmas de 6 de febrero de 2019, fundamento jurídico primero. 
desarrollo o madurez" (...) [y, por tanto] esa relación fue establecida con quien (en gran parte a causa de sus limitaciones personales) resultaba ser una persona de similar grado de desarrollo psico-sexual" ${ }^{\prime 2}$. En consecuencia, el tribunal procede a absolver al acusado, aun con la diferencia de edad apuntada entre los hermanastros.

Dicho párrafo es reproducido casi literalmente por la Sentencia de la Audiencia Provincial de La Rioja de 12 de diciembre de 2018 (valorando la relación entre dos personas de 20 y 14 años de edad), indicando que "indiscutible resulta la diferencia de edad, de algo más de cinco años (...) pero la proximidad por edad a que se refiere el precepto no puede entenderse referida sin más a la edad cronológica, sino que debe ser puesta en relación con el segundo inciso del precepto, que se refiere al "grado de desarrollo o madurez", y desde esta consideración estima el Tribunal que el grado de desarrollo de ambos estaba muy próximo a pesar de la diferencia de edad" "33.

Sin entrar en que, en ambos casos, contemplando el conjunto de las circunstancias en que se produjeron los hechos, hubiese buenas razones para la absolución, lo cierto es que se trata de una interpretación sorprendente de la cláusula, que no se acomoda, en mi opinión, con su tenor literal.

En todo caso, son dos sentencias aisladas, siendo amplísima mayoría las que -más en consonancia con la dicción legal- requieren la concurrencia de ambos requisitos ${ }^{64}$.

62 Sentencia de la Audiencia Provincial de Tenerife de 21 de marzo de 2016, fundamento jurídico 2.

63 Sentencia de la Audiencia Provincial de La Rioja de 12 de diciembre de 2018, fundamento jurídico 4.

64 Por ejemplo, entre otras, la Sentencia de la Audiencia Provincial de Las Palmas de 6 de febrero de 2019, fundamento jurídico 4, la de la Audiencia Provincial de Las Islas Baleares de 11 de julio de 2018, fundamento jurídico 3 o la de la Audiencia Provincial de La Rioja de 12 de diciembre de 2018, fundamento jurídico 4. 


\subsection{3. ¿Qué diferencia de edades es "próxima”?}

Como señalaba en su momento, la primera gran pregunta que suscita el art. 183 quater $\mathrm{CP}$ es cuándo (a falta de previsión legal) ha de entenderse que dos edades son próximas entre sí.

Pues bien, en las sentencias de las Audiencias Provinciales estudiadas es (casi) pacífica la idea de que dos edades son próximas hasta más o menos los cinco años de diferencia entre ellas.

En efecto, nos encontramos con multitud de sentencias que consideran próximas entre sí diferencias de cuatro, cinco y seis años ${ }^{65}$. En ninguna de las sentencias examinadas la diferencia de edad entre los intervinientes en la relación sexual es inferior a los 4 años, lo que puede ser debido a dos razones: que las relaciones sexuales entre personas con diferencias de edad tan exiguas no acaban judicializadas o que, lógicamente, si la diferencia de edad es poca, el acusado sea también menor, con la consabida dificultad para encontrar a través de las bases de datos jurisprudenciales las sentencias al respecto ${ }^{66}$.

Es cierto que hay una sentencia que no considera la diferencia de 4 años (la que media entre los 12 de la víctima y los 16 del autor) como "próxima" a los efectos del art.

65 Por no reseñarlas todas, me limitaré a mencionar las más recientes: Sentencia de la Audiencia Provincial de Castellón de 20 de marzo de 2019 (diferencia de 4 años), Sentencia de la Audiencia Provincial de Madrid de 12 de junio de 2019 (diferencia de 5 años) y Sentencia de la Audiencia Provincial de Burgos de 3 de abril de 2019 (diferencia de 6 años).

66 En concreto, el limitadísimo número de ellas que llegan a las bases de datos y la sola posibilidad de encontrar referencia indirecta a alguna de ellas a través de eventuales sentencias de Audiencias Provinciales resolviendo recursos. En todo caso, sólo hemos podido localizar una sentencia en la que el acusado fuese menor de edad: la sentencia 477/2014 del Juzgado de Menores número 1 de Tarragona, cuya noticia nos llega a través de la sentencia de la Audiencia Provincial de Tarragona de 20 de diciembre de 2016, que procede, por cierto, a su anulación. 
183 quater CP, si bien dicha resolución se limita a indicar ese extremo, sin ulterior argumentación ${ }^{67}$, $\mathrm{y}$, en todo caso, son abrumadora mayoría las sentencias que absuelven cuando la diferencia de edad entre los implicados no excede de los 6 años, por lo que podría decirse que se trata de una primera pauta que nos ofrece la praxis jurisprudencial de los últimos años sobre el elemento "proximidad en edad".

Cuestión distinta, en cambio, es la que concierne a diferencias de edad más abultadas, en las que la jurisprudencia está sumamente dividida, aunque es mayoritaria la opción de considerar que, por encima de los 6 años de diferencia, dichas edades no son próximas y, consecuentemente, se debe condenar al acusado por un delito de abuso sexual del art. 183 CP.

En efecto, nos encontramos con sentencias que consideran no próximas las edades que distan entre sí siete ${ }^{68}$, ocho $^{69}$, nueve ${ }^{70}$ o diez años ${ }^{71}$, siendo minoría las sentencias que dentro de este tramo cronológico aplican la cláusula Romeo y Julieta. Así, en nuestra muestra jurisprudencial, sólo hay una sentencia que considera próxima una diferencia de ocho años $^{72}$, otra que considera lo mismo respecto de los

67 Sentencia de la Audiencia Provincial de Almería de 24 de octubre de 2018. En concreto, en su fundamento jurídico primero se indica que "el autor no es persona próxima a la menor por edad ni por grado de desarrollo o madurez tal como se aprecia en la grabación". Como señalo en el texto, no se dan mayores explicaciones.

68 Sentencia de la Audiencia Provincial de Madrid de 20 de septiembre de 2017.

69 Sentencias de la Audiencia Provincial de Guipúzcoa de 6 de marzo de 2019 y de la Audiencia Provincial de Zaragoza de 15 de febrero de 2018.

70 Sentencia de la Audiencia Provincial de Almería de 17 de mayo de 2019.

71 Sentencias de la Audiencia Provincial de Madrid de 12 de enero de 2018 y de 25 de julio de 2019; de la Audiencia Provincial de Burgos de 17 de febrero de 2019 y de la Audiencia Provincial de Asturias de 15 de mayo de 2019.

72 Sentencia de la Audiencia Provincial de Navarra de 26 de septiembre de 2018. 
nueve años ${ }^{73} \mathrm{y}$, por último, una que argumenta que un sujeto de 24 años y una menor de 14 (a punto de cumplir los 15) tenían una edad próxima a pesar de separarles casi diez años ${ }^{74}$.

Esta última sentencia es, dentro de la jurisprudencia examinada, la que acepta un mayor rango de edad. Y lo hace siendo muy cuidadosa con no contradecir la jurisprudencia del Tribunal Supremo que, en sus sentencias de 15 de diciembre de 2016 y de 18 de enero de 2017, había determinado que once y veinte años no son dos edades próximas ${ }^{75}$; es decir, había condenado con una diferencia de edad entre autor y víctima de entre 8 años y medio y 9 .

En este sentido, la Audiencia Provincial de las Islas Baleares concluye que el precepto es aplicable por cuanto la madurez sexual de la menor, que contaba con casi 15 años de edad en el momento de los hechos (y no con 11, como en los casos de la jurisprudencia del Tribunal Supremo), impide apreciar un desequilibrio notorio con el acusado, ni desde el punto de vista objetivo, ni subjetivo ${ }^{76}$. "Es decir", señala la Audiencia Provincial, "aunque la diferencia de edad entre ambos jóvenes fuera de unos nueve años, el hecho de contar ella con casi quince años y él con veinticuatro, unido a que compartían entorno social, de amistad y lúdico (contexto simétrico), no puede equiparse bajo el prisma de una mera aritmética a predichos supuestos [scil. los de la jurisprudencia del Tribunal Supremo] en que la menor cuenta con once años y él con veinte, pues las vivencias, experiencias y grado de desarrollo a tan temprana edad, cualquiera que sea el contexto vital, es desigual res ipsa loquitur al inherente a un joven de veinte años"77.

73 Sentencia de la Audiencia Provincial de Tenerife de 21 de marzo de 2016.

74 Sentencia de la Audiencia Provincial de las Islas Baleares de 11 de julio de 2018.

75 Vid. supra, apartado 3.1.

76 Sentencia de la Audiencia Provincial de las Islas Baleares de 11 de julio de 2018, fundamento jurídico II.

77 Sentencia de la Audiencia Provincial de las Islas Baleares de 11 de julio de 2018, ibid. 
Asimismo, para reforzar su posición, el mencionado tribunal recuerda que la Convención Iberoamericana de Derechos de los Jóvenes incluye bajo las expresiones "joven" y "juventud" a todas las personas comprendidas entre los $15 \mathrm{y}$ los 24 años de edad, margen que también emplea la ONU a la hora de definir el término juventud y que incluye a los dos intervinientes en la relación sexual objeto del proceso ${ }^{78}$.

En todo caso, insisto, son contadas las sentencias que aplican el art. 183 quater CP por encima de los seis años de diferencia, por lo que ahí se encontraría, de algún modo, el punto de inflexión de la jurisprudencia a este respecto. Si a ello le añadimos que ninguna sentencia acepta diferencias de diez o más años como "próximas" a los efectos de la aplicación de la cláusula Romeo y Julieta ${ }^{79}$, podríamos distinguir tres tramos de edad dentro de la jurisprudencia:

- Hasta 6 años (inclusive) de diferencia, es mayoritaria la jurisprudencia que aprecia la proximidad de edades, con muy pocas excepciones.

-Entre 6 y 9 años de diferencia, es muy mayoritaria la jurisprudencia que no aprecia la mencionada proximidad, asimismo con contadas excepciones.

-10 años es el límite superior, desde el punto de vista jurisprudencial, de aplicación de la cláusula, al menos por el momento.

78 Sentencia de la Audiencia Provincial de las Islas Baleares de 11 de julio de 2018, ibid.

79 Así, entre otras, nos encontramos con condenas por exceso respecto de la "proximidad" de edad en casos en que la diferencia era de doce años (sentencias de la Audiencia Provincial de Tenerife de 31 de julio de 2018 y de la Audiencia Provincial de Madrid de 26 de junio de 2019), trece años y medio (sentencia de la Audiencia Provincial de Burgos de 3 de julio de 2018) o catorce (Sentencia de la Audiencia Provincial de Burgos de 7 de febrero de 2019). 


\subsection{4. ¿Qué es proximidad en grado de desarrollo o ma-}

durez y cómo se acredita?

Señalaba antes que este elemento de la cláusula contenida en el art. 183 quater $\mathrm{CP}$ era el que mayores críticas había recibido por la doctrina, en la medida en que tanto "grado de desarrollo" como "grado de madurez" eran conceptos vagos y, además, habrían de requerir para su acreditación una serie de indagaciones que seguramente afectasen a la vida privada tanto del acusado como de la víctima -sometida, a su vez, a examen para averiguar si su desarrollo o madurez concuerdan con los del victimario ${ }^{80}$.

Lo cierto es que parte de la predicción negativa que la doctrina arrojó en su día sobre la cláusula Romeo y Julieta ha sido certera, a la luz de la jurisprudencia examinada, en la que, en ocasiones, ciertamente, se opta por derroteros argumentativos más que discutibles y, sobre todo, de espaldas a las pruebas periciales. En cambio, siempre en la línea de complejidad y heterogeneidad que caracteriza la muestra analizada, hay otras resoluciones que entran en la valoración del requisito de igualdad de madurez y grado de desarrollo con sumo cuidado, y con apoyo en el saber experto, por así decirlo.

Más en concreto, en primer lugar, es común que las sentencias hagan alusión, como criterios para acreditar (o no) el equilibro en grado de madurez entre el menor de 16 años y la otra persona, a la existencia de amigos en común, formas de ocio parecidas, vida laboral, grado de independencia económica, contexto familiar, etc. ${ }^{81}$, lo cual parece

80 Vid. apartado 2.5. y las conclusiones finales de este trabajo.

81 Así, ad exemplum, las sentencias del Tribunal Superior de Justicia del País Vasco de 16 de octubre de 2018 (donde también se trae a colación el hecho de que el acusado tuviese tres hijos), de la Audiencia Provincial de Tenerife de 31 de julio de 2018 (igualmente, valorando que el acusado tuviese hijos) o de la Audiencia Provincial de Madrid de 20 de septiembre de 2017. 
perfectamente lógico, y en sintonía con lo expresado por la Sentencia del Tribunal Supremo de 18 de enero de 2017 que, como señalaba supra, estableció el parámetro del "equilibrio de la pareja atendiendo a (...) la edad y el espíritu y mentalidad de ambos, debiendo rechazarse los casos de desequilibrio relevantes y notorios desde el punto de vista objetivo, pero también subjetivamente cuando aquél pueda inferirse del contexto en el que tiene lugar la relación" 82 .

Lo que sí resulta, a mi juicio, criticable es la alusión que se hace en varias sentencias a la identidad de "concepto cultural" (sic) entre acusado y menor. Desde luego, "compartir concepto cultural" es una expresión carente de sentido prima facie, de modo que hube de inferir, a la luz de los hechos probados, que, en realidad, se trataba de un modo eufemístico de referirse a que ambos menores compartían origen extranjero.

La primera de las sentencias -en lo que se me alcanzaque utiliza dicha expresión es la de la Audiencia Provincial de Madrid de 17 de enero de 2017, en la que se dice lo siguiente:

"En tales condiciones es difícil considerar que existe una diferencia de edad o madurez relevante, entre la joven y el acusado, como para no aplicar el artículo 183 quater del C. Penal. Por otra parte, son jóvenes del mismo origen étnico, que tienen amigos comunes, que tienen similares formas de entretenimiento, similar concepto cultural, similar formación, similar situación socio económica y el acusado no aparenta un grado de madurez superior a su propia edad, ni una experiencia vital (ni laboral, ni personal), que permita inferir un grado de desarrollo muy superior a sus 20 años y por tanto muy superior al de la persona con la que había tenido relaciones sexuales" $"$.

82 Sentencia del Tribunal Supremo de 18 de enero de 2017, fundamento jurídico $2^{\circ}$.

83 Sentencia de la Audiencia Provincial de Madrid de 17 de enero de 2017, fundamento jurídico $2^{\circ}$. En este caso, ambos eran de origen dominicano. 
Como se puede apreciar, en esta sentencia se alude separadamente al origen étnico y al "concepto cultural", como también hace la posterior sentencia de la Audiencia Provincial de Navarra de 27 de octubre de 2017 -si bien eliminando el adjetivo "étnico"-, indicando que "se trata de unos jóvenes del mismo origen, que tienen, al parecer, similares formas de entretenimiento, concepto cultural, formación y situación socio económica" 84 . En cambio, en la posterior sentencia de la propia Audiencia Provincial de Navarra de 26 de septiembre de 2018 desaparece la referencia al origen (señalándose, sin más, que "se trata de unos jóvenes que tenían, al parecer, similares formas de entretenimiento, concepto cultural, formación y situación socio económica" ${ }^{85}$ ), para reaparecer la mención al "origen" en la Sentencia de la Audiencia Provincial de La Rioja de 12 de diciembre de 2018, junto al adjetivo "étnico", en el siguiente pasaje: "Son dos jóvenes del mismo origen étnico, con amigos comunes (grupo de whatsapp y salidas), con similares concepto cultural, formación y formas de entretenimiento" $"$.

Con lo anterior, no quiero criticar ni el hecho de que esos cuatro acusados hayan sido, a la postre, absueltos -pues hay buenas razones para ello-, ni que se haga una valoración holística de la vida de los acusados y los menores a la hora de enjuiciar su equilibrio a los efectos del art. 183 quater $\mathrm{CP}$, sino sólo alertar sobre la posibilidad de que ese tipo de argumentación canalice prejuicios culturales sobre los extranjeros (por más que sean a favor del reo), en la medida en que ninguna de la sentencias mencionadas analiza si, de hecho,

84 Sentencia de la Audiencia Provincial de Navarra de 27 de octubre de 2017, fundamento jurídico $4^{\circ}$. Acusado y menor eran de origen boliviano.

85 Sentencia de la Audiencia Provincial de Navarra de 26 de septiembre de 2018 , fundamento jurídico $4^{\circ}$. Se trataba, en este caso, de dos personas de origen peruano.

86 Sentencia de la Audiencia Provincial de La Rioja de 12 de diciembre de 2018 , fundamento jurídico $4^{\circ}$. Ambos intervinientes en la relación sexual eran de origen magrebí. 
acusado y menor tenían elementos culturales en común, dándose esto por supuesto por el mero hecho de compartir país de origen (y, naturalmente, no hay ninguna sentencia en que se analicen aspectos culturales de los intervinientes en la relación sexual en caso de que ambos sean de origen español).

En segundo lugar, como era de prever y como ya había alertado la doctrina, existen sentencias en las que se entra en detalles íntimos del acusado, pero, sobre todo, del menor o la menor para valorar la paridad de madurez a los efectos de la cláusula Romeo y Julieta: es decir, si ya habían tenido relaciones sexuales previamente, con quién, cuántas veces, si el menor o la menor tomaron o no la iniciativa a la hora de mantener dichas relaciones, etc.

Hay ejemplos que considero más que ilustrativos. Entre ellos, la sentencia de la Audiencia Provincial de Navarra de 26 de septiembre de 2018, la cual señala que "a la hora de valorar ese consentimiento libre prestado por una menor, en este caso en una relación sexual consentida, no puede obviarse la propia vivencia que de la sexualidad la misma tiene. $\mathrm{Y}$ en este aspecto debe indicarse que ha quedado acreditado que la menor María Esther, con anterioridad a tener la relación sexual imputada, mantuvo relaciones sexuales con penetración, cuando menos una o dos veces con otra persona (...) Y a ello se refirió la menor en su declaración "que empezó a tener relaciones sexuales con 11 años". Esta circunstancia debe obviamente ser valorada, y si bien no permite por sí sola concluir que no sería delictiva cualquier posterior relación sexual con persona mayor de edad, pues el C. Penal exige por la protección de la indemnidad sexual de las personas menores de edad, en la individualización de la conducta, debe razonablemente ser valorada a fin de examinar el alcance de un consentimiento libre en los términos del artículo 183 quater del C. Penal" $"$.

87 Sentencia de la Audiencia Provincial de Navarra de 26 de septiembre de 2018, fundamento jurídico $4^{\circ}$. 
En un sentido muy similar, la Sentencia de la Audiencia provincial de Navarra de 27 de octubre de 2017 indica que "no puede ignorarse que la menor indicó que ya anteriormente había consumido bebidas alcohólicas y había tenido "tres novios", según refirió a la señora psicóloga, a la que indicó que, con uno de ellos, con el que tuvo una relación de un año, mantuvo relaciones sexuales" 88 .

En un sentido muy similar, nos encontramos con la sentencia de la Audiencia Provincial de Barcelona, de 16 de febrero de 2017, donde se nos ilustra ampliamente sobre las conversaciones sexuales entre la menor (de doce años) y el acusado (de dieciocho), y, en particular, sobre la iniciativa que la menor toma en todo momento.

Así, relata la sentencia: "María Antonieta manifestó en su declaración que el acusado iba detrás de ella, que "le tiraba la caña", sin embargo, las conversaciones o mensajes de los whatsapp que se volcaron del teléfono del acusado ponen de manifiesto una notable iniciativa por parte de María Antonieta y un contenido sexual en sus palabras que acortan la distancia que parecería lógica en este ámbito, en atención a las edades de ambos.

Así, en el folio 42, puede verse una conversación entre María Antonieta y Urbano, el día 30/09/13, quince días antes de los hechos, en la que puede verse la insistencia de la menor por atraer y mantener la relación con Urbano, enviándole fotos. En fecha 01/10/13, folio 43, parecen concertar una cita y María Antonieta le dice "aun soy tuya sabes". En fecha 06/10/13, folio 44, María Antonieta sigue insistiendo en tener relación con Urbano. Desde las 20,44 a las 20,51, diciéndole que él le cae bien a su madre y que puede ir a su casa. En el folio 46, conversación de 12/10/13 nuevamente María Antonieta insiste para quedar, le dice que venga a buscarla en coche, pero él le dice que no tiene gasolina. Luego, más

88 Sentencia de la Audiencia Provincial de Navarra de 27 de octubre de 2017, fundamento jurídico $4^{\circ}$. 
adelante, él le dice que tiene un sueño, que es hacer un trío y Urbano le dice "pero con dos tíos" "yo a punto" a lo que él dice que si es así siempre hay "ostias por en medio".

María Antonieta contesta que "uno se la mete y la tía la chupa al otro y luego al revés" y él contesta "no, hay ostias, créeme" y sigue la conversación en este tema con un dialogo de marcado contenido sexual, que pone de manifiesto que no existe diferencia remarcable por razón de la edad o de otra circunstancia entre ambos (...) Es de destacar la capacidad de preparación que tiene María Antonieta para conseguir su propósito de ver a Urbano, no siendo éste quien lleva la iniciativa y presiona a la menor para tener el encuentro, sino todo lo contrario" $"$.

Como advertía la doctrina ya desde el inicio, la cláusula del art. 183 quater CP conduce a esto: sentencias con las que podemos tener una idea (demasiado) clara de la vida sexual de los menores implicados y de sus conversaciones más íntimas, para, a la postre, absolver al acusado en caso de que dicha vida sexual haya sido intensa o, sencillamente, hayan sido los menores los que hayan llevado la iniciativa del encuentro.

De nuevo, quiero subrayar que no se trata de una crítica, sino, más bien, de una consecuencia inevitable de la dicción de la cláusula, si bien hay una jurisprudencia minoritaria que considera que no necesariamente una vida sexual activa o que la relación sexual haya sido a propuesta del menor indican madurez por parte de este.

Así, en esta última línea, la Sentencia del Tribunal Superior de Justicia del País Vasco de 16 de octubre de 2018, expone que "la letrada de la defensa ha efectuado un ímprobo

89 Sentencia de la Audiencia Provincial de Barcelona, de 16 de febrero de 2017, fundamento jurídico segundo. Acto seguido, el tribunal continúa relatando otras conversaciones de similar contenido, destacando el hecho de que la menor practicase sexo por webcam a través de una aplicación de móvil. 
esfuerzo para tratar de hacer ver que Rosaura aparentaba más años y tenía un grado de madurez superior a otra adolescente de su edad refiriéndose a sus supuestos hábitos (salía hasta tarde, fumaba, había tenido relaciones previas) y alegando que, al parecer es habitual, ente personas de su etnia, mantener relaciones sexuales a temprana edad. No obstante estas alegaciones no se han acreditado y en todo caso no resultan indicativas del grado de madurez personal sino que, más bien, pueden ser compatibles con el proceso de evolución que puede producirse a la edad de la menor"90. O, como sucintamente concluye la Sentencia de 12 de enero de 2018, de la Audiencia Provincial de Madrid, "el solo hecho de que la menor no fuese sexualmente inexperta no implica proximidad en el grado de madurez"91.

En todo caso, lo corriente es que la acreditación de precocidad en el inicio de las relaciones sexuales o una clara insistencia del menor al adulto para mantenerlas sea un elemento clave a la hora de valorar la equivalencia en grado de madurez entre ambos.

Por último, en lo que respecta a este aspecto de la cláusula, cabe destacar que, a la hora de acreditar el grado de desarrollo o madurez, hay tribunales que acuden a prueba pericial (fundamentalmente psicológica), mientras que hay otros que, sencillamente, acuden a su propia percepción de la simetría física o de qué grado de madurez tenía el menor implicado en los hechos.

Paradigmática de esto último es una sentencia del Juzgado de Menores número 1 de Tarragona, en la que se señala lo siguiente: "se aprecia que entre los menores existe esa proximidad de edad, pues los separan cuatro años, y ambos están ya atravesando la etapa de la pubertad y adolescencia,

90 Sentencia del Tribunal Superior de Justicia del País Vasco de 16 de octubre de 2018, fundamento jurídico quinto.

91 Sentencia de la Audiencia Provincial de Madrid de 12 de enero de 2018, fundamento jurídico segundo. 
en un contexto con connotaciones sexuales, buscando a propósito por los dos (...) esta etapa se caracteriza por experimentar y aproximarse a los límites, probando hasta dónde se puede llegar, jugando a ser mayor, también en materia sexual, que conocido por todos que en esta etapa de la pubertad es cuando se despierta. Por otro lado, ciertamente, la víctima cuenta con 11 años, pero estaba muy próxima a los 12 (...). Es decir que no es nada nuevo, ya los romanos, el derecho canónico y nuestro Código Civil hacían la distinción, que las mujeres, en esta edad que consideramos, son más maduras que los hombres, de forma que esa diferencia de edad entre el menor acusado y la víctima no es tanta ya que la madurez entre ambos es muy próxima. Se entendía que una mujer de 12 años era tan madura como un varón de 14 años. Esta era la aproximación que hacían los romanos y que por su influencia se trasladó al derecho canónico y al derecho civil. Por tanto, ocurriendo los hechos entre adolescentes con proximidad de edad y grado de desarrollo o madurez, se considera aplicable el precepto transcrito [scil. el art. 183 quater CP]"92.

Dicha argumentación fue justamente reprochada en fase de recurso por la Audiencia Provincial, en los siguientes términos: "en cuanto a la aplicación del supuesto contemplado en el artículo 183 quater del Código Penal, el Juez extrae aquellas conclusiones sin haber realizado el más mínimo juicio crítico sobre los medios de prueba, omitiendo incluso un informe psicológico que analiza las cuestiones relativas a la madurez sexual de ambas partes, informe que ni siquiera ha sido mencionado por el Juez a quo, construyendo su conclusión de espaldas al juicio plenario, lo que la convierte en arbitraria e incontrolable. Las menciones relativas a que las mujeres, en esa edad son más maduras que los hombres, y ello no es nada nuevo ya desde los romanos, no son admisi-

92 Sentencia 477/2014 del Juzgado de Menores número 1 de Tarragona, citada por la sentencia de la Audiencia Provincial de Tarragona de 20 de diciembre de 2016 en su fundamento jurídico segundo. 
bles, al constituir meras manifestaciones arbitrarias, sin sustento en ningún tipo de fundamentación y carentes de apoyo probatorio alguno. Y ello cuando se trata de argumentación judicial equivale a irracional. Lógicamente, ante esta situación, la Sala no puede efectuar, sustituyendo la labor de instancia, una valoración de los medios de prueba personales. No es asumible que se fraccione el cuadro de prueba y menos aún que se prescinda de un discurso completo, justificativo y cognitivo de la conclusión a la que se llega, sustituyéndolo por consideraciones que se basan en ignotas y no acreditadas máximas de experiencia, lo que acerca el argumento al puro conocimiento o convencimiento privado del Juez, pues de ese modo la solución adoptada escapa del control de racionalidad por parte del órgano apelativo.

Lo anterior obliga a declarar la nulidad de la sentencia para que por parte del Juez se dicte nueva resolución que responda a las exigencias de racionalidad sustancial antes precisadas" $" 93$.

Con independencia de que, a la luz de los hechos probados, la aplicación del art. 183 quater CP pudiese estar justificada, lo cierto es que, a mi juicio, la Audiencia Provincial anuló correctamente la sentencia de instancia, en la medida en que un elemento vago como "grado de desarrollo o madurez" no puede, a su vez, ser constatado con apreciaciones subjetivas e ideas preconcebidas de los juzgadores.

Esto último sucede con más frecuencia, naturalmente, cuando directamente no se ha propuesto prueba pericial por las partes ${ }^{94}$, pero incluso habiéndose practicado hay ocasiones en que se llega a una conclusión diversa. Así, sin ir más lejos, en la antes referida sentencia de la Audiencia Provincial

93 Sentencia de la Audiencia Provincial de Tarragona de 20 de diciembre de 2016, fundamento jurídico segundo.

94 Así, sucede, entre otras, en las sentencias de la Audiencia Provincial de Madrid de 20 de septiembre de 2017 o en la de la Audiencia Provincial de Navarra de 27 de octubre del mismo año. 
de Barcelona, de 16 de febrero de 2017, se llega a la conclusión de que existe paridad en el grado de madurez "pese a las alteraciones psicológicas [de la menor] que se exponen en los informes periciales" 95 .

De todos modos, son amplia mayoría las resoluciones que basan su decisión en los informes periciales presenta$\operatorname{dos}^{96}$, lo que debe ser recibido con satisfacción, en la medida en que, por lo menos, la decisión no queda librada a la subjetividad o a las coordenadas ideológicas de los juzgadores.

3.2.5. ¿Puede aplicarse la cláusula como atenuante analógica si no se da alguno de sus requisitos?

Esta idea, la de que es posible convertir el art. 183 quater $\mathrm{CP}$ en una atenuante, en caso de que falte alguno de sus requisitos, fue puesta sobre la mesa por la Circular 1/2017, en los siguientes términos:

"El precepto sustantivo no hace referencia a la posibilidad de que, concurriendo el consentimiento y la proximidad por edad, el grado de desarrollo o madurez concurra solo parcialmente, de forma que, aunque la vulnerabilidad de la víctima y la situación de abuso exijan la aplicación de una sanción penal, atendidas las circunstancias del adulto y del menor, esta deba ser atenuada (...) El Tribunal Supremo ha considerado que pueden ser apreciadas como circunstancias atenuantes por analogía "las que se conecten con algún elemento esencial definidor del tipo penal, básico para la descripción e inclusión de la conducta en el Código penal, y que suponga la ratio de su incriminación o esté directamente relacionada con el bien jurídico protegido" (SSTS nº 516/2013,

95 Sentencia de la Audiencia Provincial de Barcelona, de 16 de febrero de 2017, fundamento jurídico segundo.

96 Así, entre otras, toman una decisión haciendo mención expresa a la prueba pericial las sentencias de la Audiencia Provincial de Vizcaya de 14 de noviembre de 2018, de Guipúzcoa de 6 de marzo de 2019, de Burgos, de 3 de abril de 2019 y de Almería, de 17 de mayo de 2019. 
de 20 de junio y 945/2013, de 16 de diciembre, entre otras). La propia rúbrica del Capítulo II bis, al referirse a "abuso" (excluyendo las conductas de agresión sexual por no obedecer a actos consensuados, como ya se dijo), indica con claridad que nos encontramos en este supuesto. La ausencia de abuso excluye la posible responsabilidad penal, pero el caso concreto puede dar lugar a que, sin llegar a este punto, haya lugar a una modulación. Debe, por tanto, admitirse la posibilidad de construir una atenuante analógica con relación al art. 183 quater cuando solo parcialmente concurran sus presupuestos exoneradores. Incluso será admisible apreciarla como muy cualificada para los supuestos en los que, sin ser admisible la exoneración total, atendidas las circunstancias concurrentes, la relación entre el autor y el menor sea cercana a la simetría en el grado de desarrollo y madurez. En todo caso siempre será imprescindible la concurrencia de consentimiento"97.

Esta idea ha sido acogida por algunas sentencias de Audiencias Provinciales ${ }^{98}$ y ha servido para aminorar sustancialmente la pena resultante de la aplicación estricta del art. 183 CP. Así, por ejemplo, la sentencia de la Audiencia Provincial de Vizcaya de 14 de noviembre de 2018 aplica como cualificada dicha atenuante indicando que: "sentada la existencia de consentimiento a mantener la relación sexual por parte de la menor y que existe proximidad entre las edades de ambos (se llevan cinco años, habiendo alcanzado el encausado la mayoría de edad poco tiempo antes de la fecha de los hechos) falta sin embargo esa identidad o simetría en el desarrollo o madurez entre el autor y la menor, tal y como consta en los informes periciales elaborados por la forense Sra. Almudena reseñados más arriba y que ratificó y aclaró

97 FISCALÍA GENERAL DEL ESTADO, Circular 1/2017, cit., p. 8 y 9.

98 En concreto, las Sentencias de la Audiencia Provincial de Vizcaya de 14 de noviembre de 2018, de la Audiencia Provincial de Las Palmas, de 6 de febrero de 2019 y de la Audiencia Provincial de Almería, de 16 de mayo de 2019. 
en la vista oral, donde dijo que la dismetría era clara pero sin poder afirmar que fuera total. Así las cosas, y toda vez que concurren dos de los tres elementos de la exclusión de responsabilidad penal que contempla el $\operatorname{art}^{\circ} 183$ quáter $\mathrm{CP}$ (consentimiento y edades próximas) siendo una de ellas -el consentimiento- fundamental y en cuanto a la tercera (grado de madurez) tampoco era inexistente, puede articularse una atenuante de análoga significación a aquella, en tanto que existe una semejanza intrínseca entre la conducta apreciada y la contemplada en el texto legal, atenuante que ha de reputarse cualificada precisamente por concurrir plenamente dos de los tres elementos de la exclusión, siendo uno de ellos el sustancial (el consentimiento)"99.

El recurso a esta idea de la atenuante analógica (como el recurso, a veces, a mi juicio, un tanto forzado, a aplicar el error de prohibición invencible al autor ${ }^{100}$ ) supone, en mi opinión, una huida de los órganos jurisdiccionales del punitivismo extremo que el actual art. $183 \mathrm{CP}$ impone, lo que resulta, creo, difícilmente reprochable.

\section{Algunas conclusiones globales}

En la primera parte de este trabajo expuse las principales dudas y conclusiones de la doctrina que ha estudiado el art. 183 quater desde su introducción en nuestro Código penal $\mathrm{y}$, en la segunda, (casi) todas las sentencias que han resuelto procesos en que se había alegado dicha cláusula

99 Sentencia de la Audiencia Provincial de Vizcaya de 14 de noviembre de 2018, fundamento jurídico quinto. Se le rebaja la pena un grado, en consecuencia.

100 Así lo hacen, por ejemplo, las sentencias de la Audiencia Provincial de Burgos de 7 de febrero de 2019 y de la Audiencia Provincial de Castellón de 20 de marzo de 2019. Sobre las alegaciones de error (de tipo o de prohibición) en la jurisprudencia sobre el art. 183 del Código Penal no abundaré, por no ser objeto de este estudio y merecer, sin duda, uno específico. 
Romeo y Julieta. Como el lector habrá podido apreciar, hay notables diferencias entre el Law in the books doctrinal y el Law in action de la jurisprudencia, por más multiforme y cambiante que ésta sea.

En todo caso, no obstante, pueden extraerse varias conclusiones que pueden, en mi opinión, orientar a quien -sea desde el punto de vista teórico, sea desde el prácticoaborde esta compleja problemática del consentimiento de relaciones sexuales por parte de los menores de dieciséis años.

La primera, por más obvio que sea indicar esto, es que la reforma de 2015 supuso un notable impacto en la criminalización de las relaciones sexuales con adolescentes. Esto, que había sido subrayado a priori -como vimos- por la práctica totalidad de la doctrina, se ha visto refrendado por la praxis jurisprudencial.

Hay un dato que es, creo, suficientemente expresivo: 14 de las 38 condenas que han recaído en estos años en supuestos en que se había alegado el art. 183 quater $\mathrm{CP}$, habrían sido absoluciones antes de la reforma de 2015 (por tener la víctima más de trece años: condición necesaria y, unida al consentimiento, suficiente para hacer impune la conducta en la regulación anterior). Sólo hay un supuesto, entre el medio centenar examinado, en el que se produce una absolución que habría sido una condena con anterioridad a la entrada en vigor de la reforma de $2015^{101}$, al tener el acusado 18 años y la menor sólo $12^{102}$.

Una segunda conclusión, siempre con matices, es que se está asentando la idea de que hasta los 5 o 6 años de diferencia entre el menor y el otro interviniente en la relación

101 Me refiero a la Sentencia de la Audiencia Provincial de Barcelona de 16 de febrero de 2017.

102 Esto último da la razón a aquellos autores que -como señalé en el apartado 2.3.- han sostenido que el art. 183 quater no contaba con límite inferior de edad de aplicación. 
sexual, la regla ha de ser la absolución, mientras que, entre los 6 y los 10 años de diferencia cronológica, la regla ha de ser considerar que no se trata de edades próximas. Por encima de los diez años, es unánime la jurisprudencia que excluye la aplicación del art. 183 quater CP. Esto supone un punto de convergencia entre doctrina y jurisprudencia, en la medida en que aquélla -como vimos en el apartado 2.4.- ha realizado propuestas en un sentido muy similar.

En tercer lugar, el espinoso elemento de la cláusula "proximidad en grado de desarrollo o madurez", sobre el que tanto ha alertado la doctrina, está siendo tratado, a mi juicio, con bastante cautela por parte de la jurisprudencia.

En efecto, aunque abundan las menciones a aspectos íntimos sobre el desarrollo físico y la vida sexual de los menores involucrados, lo cierto es que, por lo general, los órganos jurisdiccionales se están basando en informes periciales psicológicos o médicos, por lo que la permeabilidad de la jurisprudencia a consideraciones puramente ideológicas se mantiene en niveles inferiores a los que la doctrina se temió desde un inicio. Ello no obstante, convendría estar alerta sobre el posible sesgo de los tribunales cuando ambos intervinientes en la relación sexual son de origen extranjero, como puse de manifiesto en el apartado 3.2.4.

Por último, lo cierto es que la lectura del medio centenar de resoluciones que he examinado para la realización de este trabajo me ha ilustrado ampliamente sobre aspectos personales, sexuales y familiares de los menores de dieciséis años que consintieron tener una relación sexual con un adulto. Ciertamente, es necesario que los tribunales cuenten con toda esa información, desde el momento en que el precepto exige que se analice el desarrollo y la madurez tanto de la víctima como del acusado, lo que, desde luego, comporta la realización de prueba al respecto. Mi reticencia, por tanto, es extrajurídica, y tiene que ver, precisamente, con el aspecto personal de los menores que protagonizan estas sentencias: 
en concreto, con lo duro que ha debido de ser para muchos de ellos el proceso en sí e, incluso, su vida después de él.

Me voy a explicar a través de un ejemplo. En la detallada sentencia de la Audiencia Provincial de Castellón de 20 de marzo de 2019 se nos relatan, entre otras, las siguientes cuestiones: que la menor (la cual tenía trece años en el momento de los hechos) tenía problemas de control de los impulsos, que se había llegado a lesionar alguna vez, que se había tratado de su primera relación sexual, que consideraba a su madre "una loca", que planeaba escaparse de casa de ésta, que le costaba distinguir realidad y ficción, que estaba obsesionada con los videojuegos, y que había enviado fotos pornográficas al acusado. Y todos esos datos han transcendido por testimonios de la propia menor (quien declaró, señala la sentencia, "con evidentes síntomas de ansiedad a la hora de responder" ${ }^{103}$ ), del acusado, de compañeros de clase, amigas, familiares, psicólogos, etc.

Insisto en que todo lo anterior no era en absoluto baladí para llegar a una correcta aplicación de la cláusula y, por tanto, está plenamente justificado desde el punto de vista penal / procesal. Pero esa necesidad, que exige el art. 183 quater $\mathrm{CP}$, de indagar en la vida de los menores de dieciséis años involucrados, coloca a éstos en una situación que podría ser calificada de victimización secundaria si no fuese porque (como en el caso anterior) toda esa indagación puede llevar, a la postre, a la absolución de la persona acusada, en aplicación de la cláusula Romeo y Julieta y, en consecuencia, no habría una "víctima" (al menos no en el sentido criminológico del término) en ese supuesto. Pero sí la hay, en mi opinión, desde el punto de vista del respeto al principio del superior interés de los menores que permea nuestro ordenamiento jurídico.

103 Sentencia de la Audiencia Provincial de Castellón de 20 de marzo de 2019, fundamento jurídico primero. 
En este sentido, como indicaba antes, si alguna conclusión hay que sacar del recorrido que ha tenido estos años el art. 183 quater CP no es, desde luego, que haya tenido o dejado de tener consecuencias sobre la protección de los menores frente a los abusos (ésta es una cuestión que depende sustancialmente de cómo concibamos la esfera sexual de los menores y su grado de libertad respecto de ella) sino que ha tenido sin duda alguna un importante impacto institucional sobre ellos. En el caso que indicaba antes, esa menor (insisto, de 13 años en el momento de los hechos, 14 en el momento de la vista oral) ha sido examinada por médicos y por psicólogos, ha declarado ante la policía, el Juzgado de Instrucción y la Audiencia Provincial, ha visto cómo se razonaba acerca de su madurez y sus problemas de conducta, cómo se leían sus mensajes -sexuales y no sexuales-, ha oído declarar a sus amigas acerca de ella, su vida sexual y las confidencias que sobre su madre les había confiado, etc. El resultado, como digo, es que el acusado fue absuelto y ella retomó su convivencia con una madre que ahora sabe cuál es la opinión de su hija sobre ella, y en un entorno que le ha dado la espalda (pues la sentencia sugiere que las que eran sus amigas en aquel momento ya no lo son, a resultas de estos hechos).

Me pregunto si todo ese escrutinio y sus previsibles consecuencias en la vida de esa menor (y de los demás menores sobre cuyas vidas sabemos a través de las sentencias analizadas) es proporcional al objetivo de protección para el que, al menos en teoría, nació la reforma del 2015 y, con ella, la cláusula Romeo y Julieta. Me pregunto también si ése es el mejor modo en que los adultos y esa poderosa arma nuestra que es el ius puniendi podemos proteger a los menores sin desempoderarlos en su esfera personal. Y me temo que ambas respuestas son negativas. 


\section{Bibliografía}

BOIX REIG, J., "Delitos contra la libertad e indemnidad sexuales (IV)", en BOIX REIG, J. (coord.), Derecho penal. Parte especial, $2^{\mathrm{a}}$ edición, Iustel, Madrid, 2016, pp. 399 y ss.

BOLDOVA PASAMAR, M. A., "Delitos contra la libertad e indemnidad sexuales (I), en ROMEO CASABONA, C. M. / SOLA RECHE, E. / BOLDOVA PASAMAR, M. A. (coords.), Derecho penal. Parte especial, Comares, Granada, 2016, pp. 191 y ss.

CABRERA MARTÍN, M., La victimización sexual de menores en el Código penal español y en la política criminal internacional, Dykinson, Madrid, 2019.

CANCIO MELIÁ, M., "Delitos contra la libertad e indemnidad sexuales", en AA.VV., Memento práctico Francis Lefebvre. Penal. 2018, Francis Lefebvre, Madrid, 2018, pp. 1032 y ss.

CONSEJO DE ESTADO, Dictamen 358/2013 de 27 de junio, sobre el Anteproyecto de ley orgánica por la que se modifica la Ley Orgánica 10/1995, de 23 de noviembre, del Código Penal, (disponible en: http://www.boe.es/ buscar/doc.php?id=CE-D-2013-358).

CUERDA ARNAU, Mª. L., "Irracionalidad y ausencia de evaluación legislativa en las reformas de los delitos sexuales contra menores", en Revista electrónica de Ciencia penal y Criminología, número 10-09, 2017.

ESCOBAR JIMÉNEZ, R., "Delitos contra la libertad e indemnidad sexuales", en DEL MORAL GARCÍA, A. (dir.), Código penal: comentarios y jurisprudencia, $4^{\mathrm{a}}$ ed., Tomo I, Comares, Granada, 2018, pp. 981 y ss.

FISCALÍA GENERAL DEL ESTADO, Circular 1/2017, sobre la interpretación del art. 183 quater del Código penal, (disponible en https://www.boe.es/buscar/abrir fiscalia.php?id=FIS-C-2017-00001.pdf).

FISCALÍA GENERAL DEL ESTADO, Circular 9/2011 de 16 de noviembre, sobre criterios para la unidad de 
actuación especializada del Ministerio Fiscal en materia de reforma de menores, p. 18 (disponible en: https://www.boe.es/buscar/abrir_fiscalia.php?id=FISC-2011-00009.pdf).

GARCÍA ÁLVAREZ, P., "La nueva regulación de los delitos contra la libertad e indemnidad sexual tras la reforma operada en el Código penal por la LO 1/2015, de 30 de marzo", en Cuadernos penales José María Lidón, número 12, 2016, pp. 261 y ss.

GÓMEZ TOMILLO, M., "Artículo 183 quater", en GÓMEZ TOMILlO, M. (dir.), Comentarios prácticos al Código penal, Tomo II, Aranzadi, Cizur Menor, 2015, pp. 535 y ss.

GONZÁlEZ AGUDELO, G., "Consecuencias jurídicas y político - criminales de la elevación de la edad del consentimiento sexual en los derechos sexuales y de salud sexual y reproductiva del menor de edad", en Revista electrónica de Ciencia penal y Criminología, número 18-15, 2016.

JAÉN VALLEJO, M. PERRINO PÉREZ, A. L., La reforma penal de 2015: análisis de las principales reformas introducidas en el Código penal por las Leyes Orgánicas 1 y 2/2015, de 30 de marzo, Dykinson, Madrid, 2015.

JAMES, S., "Romeo and Juliet were sex offenders: an analysis of the age of consent and a call for reform", en University of Missouri-Kansas City Law review, vol. 78, 2009, pp. 241 y ss.

MAÑAS DE ORDUÑA, A., "Delitos contra la libertad e indemnidad sexuales", en ZÁRATE CONDE, A. (coord.), Derecho penal. Parte especial, $2^{\mathrm{a}}$ edición, Centro de Estudios Ramón Areces, Madrid, 2018, pp. 167 y ss.

MORILLAS FERNÁNDEZ, D. L., "Los delitos contra la libertad e indemnidad sexuales", en MORILLAS CUEVA, L: (dir.), Estudios sobre el Código penal reformado (Leyes Orgánicas 1/2015 y 2/2015), Dykinson, Madrid, 2015, pp. 433 y ss. 
ORTS BERENGUER, E., "Delitos contra la libertad e indemnidad sexuales (II)", en GONZÁLEZ CUSSAC, J. L. (coord.): Derecho penal. Parte especial, $6^{a}$ edición, Tirant lo Blanch, Valencia, 2019, pp. 217 y ss.

RAGUÉS I VALLÉS, R., "Delitos contra la libertad e indemnidad sexuales", en SILVA SÁNCHEZ, J. M ${ }^{\mathrm{a}}$ (dir.) / RAGUÉS I VALLÉS, R. (coord.), Lecciones de Derecho penal. Parte especial, cuarta edición, Atelier, Barcelona, 2015, pp. 129 y ss.

RAMOS VÁZQUEZ, J. A., Politica criminal, cultura y abuso sexual de menores: un estudio sobre los artículos 183 y siguientes del Código penal, Tirant lo Blanch, Valencia, 2016.

REITZ-KRUEGER, C. L. / WARNER, T. C. / NEWSHAM, R. L. / REPUCCI, N. D., "Who's to blame? Perceptions of adolescents' maturity and responsibility in sexual relationships with an older partner", en Psychology, public policy and Law, número 22 (1), 2016, pp. 105 y ss. https://doi.org/10.1037/law0000065

ROPERO CARRASCO, J., "Reformas penales y política criminal en la protección de la indemnidad sexual de los menores. El proyecto de 2013", en Estudios penales y criminológicos, 34, 2014, pp. 225 y ss.

SUÁREZ-MIRA RODRÍGUEZ, C., “Tema 32”, en SUÁREZ-MIRA RODRÍGUEZ, C. (dir.), Manual de Derecho penal. Parte especial, $7^{\text {a }}$ edición, Aranzadi, Cizur Menor, 2018, pp. 221 y ss.

TAMARIT SUMALLA, J. M". ., "Delitos contra la indemnidad sexual de menores", en QUINTERO OLIVARES, G. (dir.), Comentario a la reforma penal de 2015, Aranzadi, Cizur Menor, 2015, pp. 421 y ss.

TAMARIT SUMALLA, J. M ${ }^{\mathrm{a}}$., "Artículo 183 quater", en QUINTERO OLIVARES, G., Comentarios al Código penal español, $7^{\text {a }}$ edición, Aranzadi, Cizur Menor, 2016, pp. 1331 y ss. 


\section{Jurisprudencia analizada}

Sentencia del Tribunal Supremo de 14 de octubre de 2019 [T.O.L. 7.567.723].

Sentencia del Tribunal Supremo de 18 de enero de 2017 [T.O.L. 5.944.254].

Sentencia del Tribunal Supremo de 15 de diciembre de 2016 [T.O.L. 5.916.823].

Auto del Tribunal Supremo de 12 de septiembre de 2019 [T.O.L. 7.542.658].

Auto del Tribunal Supremo de 23 de marzo de 2017 [T.O.L. 6.072.830].

Auto del Tribunal Supremo de 21 de enero de 2016 [T.O.L. 5.637.307].

Sentencia del Tribunal Superior de Justicia de Madrid de 6 de febrero de 2019 [T.O.L. 7.110.652].

Sentencia del Tribunal Superior de Justicia de Madrid de 22 de noviembre de 2018 [T.O.L. 6.988.060].

Sentencia del Tribunal Superior de Justicia del País Vasco de 16 de octubre de 2018 [T.O.L. 6.917.468].

Sentencia de la Audiencia Provincial de A Coruña de 22 de abril de 2019 [T.O.L. 7.220.418].

Sentencia de la Audiencia Provincial de A Coruña de 22 de marzo de 2018 [T.O.L. 6.632.511].

Sentencia de la Audiencia Provincial de Almería de 17 de mayo de 2019 [T.O.L. 7.445.891].

Sentencia de la Audiencia Provincial de Almería de 16 de mayo de 2019 [T.O.L. 7.444.541].

Sentencia de la Audiencia Provincial de Almería de 24 de octubre de 2018 [T.O.L. 7.010.742].

Sentencia de la Audiencia Provincial de Asturias de 27 de septiembre de 2019 [T.O.L. 7.541.359]. 
Sentencia de la Audiencia Provincial de Asturias de 15 de mayo de 2019 [T.O.L. 7.336.118].

Sentencia de la Audiencia Provincial de Badajoz de 9 de julio de 2019 [T.O.L 7.434.384].

Sentencia de la Audiencia Provincial de Badajoz de 17 de julio de 2018 [T.O.L. 6.875.737].

Sentencia de la Audiencia Provincial de Barcelona de 22 de mayo de 2018 [T.O. L. 7.076.745].

Sentencia de la Audiencia Provincial de Barcelona de 16 de febrero de 2017 [T.O.L. 6.094.979].

Sentencia de la Audiencia Provincial de Burgos de 26 de abril de 2019 [T.O.L. 7.496.476].

Sentencia de la Audiencia Provincial de Burgos de 3 de abril de 2019 [T.O.L. 7.201.504].

Sentencia de la Audiencia Provincial de Burgos de 7 de febrero de 2019 [T.O.L. 7.099.170].

Sentencia de la Audiencia Provincial de Burgos de 13 de diciembre de 2018 [T.O.L. 7.025.269].

Sentencia de la Audiencia Provincial de Burgos de 3 de julio de 2018 [T.O.L. 6.843.312].

Sentencia de la Audiencia Provincial de Castellón de 20 de marzo de 2019 [T.O.L. 7.203.046].

Sentencia de la Audiencia Provincial de Cuenca de 27 de noviembre de 2018 [T.O.L. 7.090.747].

Sentencia de la Audiencia Provincial de Guadalajara de 22 de febrero de 2019 [T.O. L. 7.239.239].

Sentencia de la Audiencia Provincial de Guipúzcoa de 6 de marzo de 2019 [T.O.L. 7.263.231].

Sentencia de la Audiencia Provincial de Huesca de 29 de noviembre de 2016 [T.O.L. 5.937.312].

Sentencia de la Audiencia Provincial de La Rioja de 12 de diciembre de 2018 [T.O.L. 6.996.624]. 
Sentencia de la Audiencia Provincial de las Islas Baleares de 11 de julio de 2018 [T.O.L. 6.877.894].

Sentencia de la Audiencia Provincial de Las Palmas de 6 de febrero de 2019 [T.O.L. 7.340.885].

Sentencia de la Audiencia Provincial de Madrid de 25 de julio de 2019 [T.O.L. 7.464.345].

Sentencia de la Audiencia Provincial de Madrid de 26 de junio de 2019 [T.O.L. 7.434.972].

Sentencia de la Audiencia Provincial de Madrid de 12 de junio de 2019 [T.O.L. 7.390.523].

Sentencia de la Audiencia Provincial de Madrid de 18 de octubre de 2018 [T.O.L. 6.977.583].

Sentencia de la Audiencia Provincial de Madrid de 18 de septiembre de 2018 [T.O.L. 6.989.588].

Sentencia de la Audiencia Provincial de Madrid de 12 de junio de 2018 [T.O. L. 6.770.489].

Sentencia de la Audiencia Provincial de Madrid de 12 de enero de 2018 [T.O.L. 6.541.290].

Sentencia de la Audiencia Provincial de Madrid de 20 de septiembre de 2017 [T.O.L. 6.401.399].

Sentencia de la Audiencia Provincial de Madrid de 17 de enero de 2017 [T.O.L. 5.990.697].

Sentencia de la Audiencia Provincial de Murcia de 23 de noviembre de 2018 [T.O.L. 7.093.127].

Sentencia de la Audiencia Provincial de Navarra de 26 de septiembre de 2018 [T.O.L. 6.983.472].

Sentencia de la Audiencia Provincial de Navarra de 27 de octubre de 2017 [T.O.L. 6.483.101].

Sentencia de la Audiencia Provincial de Tarragona de 20 de diciembre de 2016 [T.O.L. 5.986.822].

Sentencia de la Audiencia Provincial de Tenerife de 31 de julio de 2018 [T.O.L. 7.027.774]. 
Sentencia de la Audiencia Provincial de Tenerife de 21 de marzo de 2016 [T.O.L. 5.703.972].

Sentencia de la Audiencia Provincial de Valladolid de 21 de junio de 2018 [T.O.L. 6.804.792].

Sentencia de la Audiencia Provincial de Vizcaya de 14 de noviembre de 2018 [T.O.L. 7.157.313].

Sentencia de la Audiencia Provincial de Zaragoza de 15 de febrero de 2018 [T.O.L. 6.576.450]. 